\title{
Directed Search in the Housing Market*
}

\author{
James Albrecht ${ }^{\dagger} \quad$ Pieter A. Gautier ${ }^{\ddagger} \quad$ Susan Vroman ${ }^{\S}$
}

August 2010

\begin{abstract}
In this paper, we present a directed search model of the housing market. The pricing mechanism we analyze reflects the way houses are bought and sold in the United States. Our model is consistent with the observation that houses are sometimes sold above, sometimes below, and sometimes at the asking price. We consider two versions of our model. In the first version, all sellers have the same reservation value. In the second version, there are two seller types, and type is private information. For both versions, we characterize the equilibrium of the game played by buyers and sellers, and we prove efficiency. Our model offers a new way to look at the housing market from a search-theoretic perspective. In addition, we contribute to the directed search literature by considering a model in which the asking price (i) entails only limited commitment and (ii) has the potential to signal seller type.
\end{abstract}

Key Words: Directed Search, Housing

JEL codes: D83, R31

${ }^{*}$ This paper has benefited from comments received at several seminars and conferences. We particularly thank V. Bhaskar and Ludo Visschers. We also thank Mike Peters for helpful correspondence on the material treated in Section 3.4.

${ }^{\dagger}$ Georgetown University and IZA

${ }^{\ddagger}$ Vrije Universiteit Amsterdam, Tinbergen Institute, CEPR and IZA.

${ }^{\S}$ Georgetown University and IZA 


\section{Introduction}

In this paper, we present a directed search model of the housing market. We construct our model with the following stylized facts in mind. First, sellers post asking prices, and buyers observe these announcements. Second, there is not a straightforward relationship between the asking price and the final sales price. Sometimes buyers make counteroffers, and houses sell below the asking price. Sometimes houses sell at the asking price. Sometimes - typically when the market is hot - houses are sold by auction above the asking price. Third, a seller who posts a low asking price is more likely to sell his house, albeit at a lower price, than one who posts a higher asking price. ${ }^{1}$

Our model is one of directed search in the sense that sellers use the asking price to attract buyers. However, ours is not a standard directed search model in that we assume only limited commitment to the asking price. The specific form of commitment that we assume reflects the institutions of the U.S. housing market. Within a "selling period," buyers who view a house that is listed at a particular price can make offers on that house. A seller is free to reject any offer below her asking price, but she also has the option to accept such an offer. However, if the seller receives one or more bona fide offers to buy the house at her asking price (without contingencies), then she is committed to sell. ${ }^{2}$ If the seller receives only one such offer at the asking price, then she is committed to transfer the house to the buyer at that price. If the seller receives two or more legitimate offers at her asking price, then she cannot, of course, sell the house to more than one buyer. In this case, the remaining buyers can bid against each other to buy the house. In practice, this auction often takes the form of bids with escalator clauses. For example, if a house is listed at $\$ 1$ million, a buyer might submit a bid of that amount together with an offer to beat any other offer the seller might receive by $\$ 5,000$ up to a maximum of $\$ 1.1$ million.

Our description of the U.S. housing market is stylized in the sense that there is sometimes ambiguity about what constitutes a bona fide offer at the asking price. For example, a seller can often reject a prospective buyer's offer at the asking price if the buyer's ability to secure a mortgage is in question. It is also important to emphasize that the institutional form of limited commitment to the asking price that we are ascribing to the U.S. housing market is not universal. For example, in the Netherlands, the asking price entails no legal commitment whatsoever. Nonetheless, since real estate agents have reputational concerns, asking prices reflect some limited commitment there as well.

\footnotetext{
${ }^{1}$ Ortalo-Magné and Merlo (2004), using UK data, find that a lower asking price increases the number of visitors and offers that a seller can expect to receive but decreases the expected sales price. Similarly, using Dutch data, De Wit and Van der Klaauw (2010) show that list price reductions significantly increase the probability of selling a house.

${ }^{2}$ This commitment is typically written into contracts between sellers and their real estate agents.
} 
Given limited commitment, what determines the asking prices that sellers post and what role do these asking prices play? Of course, the asking price for a spacious house that is located in a desirable neighborhood is typically higher than the asking price for a smaller house in a less desirable neighbourhood. We assume that prospective buyers can observe these and more subtle "vertical" differences among houses, either directly or with the help of real estate agents. Instead, we focus on the role that asking prices play in directing search across houses that buyers view as ex ante identical. In particular, we are interested in the question of whether asking prices can direct buyers towards "motivated sellers," that is, those who are particularly eager to sell and are therefore more likely to accept a low counteroffer.

We begin, however, with a basic version of our model in which all sellers are equally motivated, i.e., have the same reservation value. This homogeneous-seller version of our model turns out to be of interest in its own right. After observing all the asking prices in the market, each buyer chooses a seller to visit. Upon visiting the seller, the buyer decides how much he likes her house; that is, he observes the realization of a matchspecific random variable. This realization is the buyer's private information. Based on this realization - and without knowing how many other buyers have visited this seller the buyer chooses among accepting the seller's asking price, making a counteroffer (and, if so, at what level), or simply walking away. The seller then assembles her offers, if any. If no buyer has offered to pay the asking price, the seller decides whether or not to accept her best counteroffer. If she has received one, and only one, offer at the asking price, then she sells the house at that price. If she has received multiple offers at the asking price, she then allows the buyers who made those offers to compete for the house via an ascending bid auction. A payoff-equivalence result holds for this version of the model. All asking prices at or above the seller's reservation value give the seller the same expected payoff; asking prices below the reservation value yield a lower expected payoff. Similarly, buyers are indifferent with respect to any asking price greater than or equal to the common reservation value but strictly prefer any asking price below that level. Any distribution of asking prices greater than or equal to the common seller reservation value constitutes an equilibrium, and there are no equilibria in which any sellers post asking prices below the common reservation value. We show that these equilibria are constrained efficient; i.e., given the search frictions, equilibrium entails the optimal entry of sellers.

The homogeneous-seller version of our model is closely related to Peters and Severinov (1997), who considered a large market in which sellers compete in reserve prices for second-price auctions. In one version of their model, precisely as in our setup, buyers learn their valuations only after selecting sellers. The difference between our models is 
that we assume limited commitment to the posted reserve price - sellers cannot commit themselves to not considering counteroffers. As noted above, however, one equilibrium in the homogeneous-seller version of our model entails all sellers posting an asking price equal to the common reservation value, in which case counteroffers are not an issue. This contradicts Peters and Severinov (1997), who claim that the symmetric equilibrium reserve price does not fall to the common reservation value in this variant of the competing auctions problem. We resolve this contradiction by adapting our proof of existence in the homogeneous-seller case to show that the Peters and Severinov (1997) claim is incorrect - the symmetric equilibrium reserve price in their model equals the common seller reservation value.

After analyzing the homogeneous-seller case, we consider a version of our model in which sellers have different reservation values and in which these reservation values are private information. Specifically, we examine a model in which there are two seller types - one group with a high reservation value, the other with a low reservation value. In this heterogeneous-seller version of our model, the asking price can potentially signal a seller's type. Our signaling model is nonstandard in the sense that sellers have both $e x$ ante and ex post signaling motives. Ex ante a seller wants to signal that her reservation value is low. This attracts buyers since buyers prefer to visit a seller who is perceived to be "weak." Ex post, however, that is, once any buyers have visited, a seller prefers to have signaled a high reservation value. Buyers will be less aggressive when dealing with a seller who is perceived to be "strong." ${ }^{3}$ In separating equilibrium, the two seller types are identified by their posted asking prices. We develop the necessary and sufficient conditions for the existence of separating equilibria and demonstrate the existence of such equilibria. Separating equilibria are constrained efficient. As in the homogeneousseller case, the level of entry by sellers is optimal. In addition, the equilibrium allocation of buyer visits across the two seller types is the same as the allocation that a social planner would choose, and - this is an issue that could not arise in the homogeneousseller case - once buyers and sellers match, no mutually profitable transactions are left unconsumated.

We also consider the possibility of pooling equilibria. Given the mixed incentives that sellers face, there are potentially two types of pooling equilibria. In a pooling-on-low equilibrium, all sellers post a low asking price - the sellers with the high reservation value mimic those with the low reservation value - while in a pooling-on-high equilibrium, all sellers post a high asking price - the sellers with the low reservation value mimic those with the high reservation value. We develop the necessary and sufficient conditions

\footnotetext{
${ }^{3}$ The same mixed incentives apply in the labor market. Ex ante a job applicant wants to convince a prospective employer that she really wants the job; ex post, i.e., once the employer has decided to offer her the job, she wants the employer to believe that she has many other good options.
} 
for the existence of pooling equilibria and prove that these conditions are not satisfied. Finally, we consider the possibility of hybrid equilibria. Again, there are potentially two types of equilibria. In one possible hybrid equilibrium, some but not all of the sellers with the low reservation value mimic those with the high reservation value, while in the other possible hybrid equilibrium, some but not all of the sellers with the high reservation value mimic those with the low reservation value. We develop the necessary and sufficient conditions for such equilibria to exist and show numerically that these conditions are not satisfied.

Our paper contributes to the growing literature that uses an equilibrium search approach to understand the housing market. Search theory is a natural tool to use to analyze this market since it clearly takes time and effort for buyers to find suitable sellers and vice versa. Papers that use search theory to analyze the housing market include Wheaton (1990), Albrecht et al. (2007), and Díaz and Jerez (2009). Most of the papers in this literature assume that search is random, as opposed to directed. In some of these papers, prices are determined by Nash bargaining; in others, when a buyer and seller meet, one of the parties (typically the seller) makes a take-it-or-leave-it offer. In contrast, in our model and in Díaz and Jerez (2009), sellers post prices to attract buyers. Díaz and Jerez (2009) use competitive search theory (Moen 1997) to analyze the problem initially posed in Wheaton (1990), in which shocks lead to mismatch, causing a household to first search to buy a new house and then to look for a buyer for its old house. In their equilibrium, all sellers post the same asking price, the asking price and the sales price are the same, and all houses sell with the same probability. Our model takes a different tack in that we allow for sales to take place below, at and above the asking price. In addition, we allow for different reservation prices across sellers.

We also contribute to the directed search literature. In the standard directed search model, there is full commitment in the sense that all transactions must take place at the posted price. In our model, however, there is only limited commitment. The posted price "means something" and is used to attract buyers, but the final selling price need not be the same as the posted price. Camera and Selcuk (2009) also consider a model of directed search with limited commitment. As we do, they assume that sellers post prices and that buyers direct their search in response to those postings. The difference between our approach and theirs comes once buyers choose which sellers to visit. They allow for the possibility of renegotiation, that is, that the final selling price and the posted price may differ, but they are agnostic about the specifics of the renegotiation process. Instead, they deduce some implications of assuming that the selling price is increasing in (i) the asking price and (ii) the number of buyers who visit the seller in question; for example, they prove that all sellers post the same asking price in symmetric 
equilibrium. ${ }^{4}$ Our approach differs from that of Camera and Selcuk (2009) in that we assume a specific price determination mechanism. We take this more specific approach because the price determination mechanism that we analyze is an important one in practice and because, as we show below, it turns out that this mechanism is efficient.

We also add to the directed search literature by considering the potential signaling role of the asking price. As in Delacroix and Shi (2008), we consider a model in which the asking price plays the dual role of directing buyer search and signaling seller type. ${ }^{5}$ In their model, each seller chooses a pricing mechanism - either price posting or Nash bargaining - and whether to produce a low-quality or a high-quality good. Efficiency has two dimensions, entry and quality, and they ask under what conditions price posting or bargaining is the more efficient mechanism. The answer depends on the bargaining power parameter and on the relative quality of the two goods. In the heterogeneousseller version of our model, there are also two choice variables in the social planner problem. Seller entry should be at the efficient level, and the probability that a buyer visits a high-type seller should be at the efficient level. The pricing mechanism that we analyze is able to satisfy these two criteria simultaneously. In particular, when buyers are heterogeneous and their type is private information, an auction is an efficient selling mechanism.

In constructing our model, we have abstracted from some important features of the housing market. One obvious abstraction is that we ignore real estate agents. We do this to keep our model simple but also because the decision about the asking price, which is the focus of our model, is ultimately the seller's to make. We also abstract from the fact that in the housing market, buyers are often also sellers and their ability to buy may hinge on their ability to sell. Rather than modeling this explicitly as in Wheaton (1990) and Díaz and Jerez (2009), we capture this in the heterogeneous-seller version of our model through the reservation value. A motivated seller, one with a low reservation value, can be thought of as one who has already bought or put a contract on a new house and is thus eager to sell. Finally, houses are, of course, not identical - some are in good condition and located in desirable neighborhoods while others are not - and much of the variation in asking prices across houses reflects this intrinsic heterogeneity.

\footnotetext{
${ }^{4}$ As we show below, in the equilibrium of the homogeneous-seller version of our model, the expected selling price is not increasing in the asking price. More fundamentally, our model does not fit the Camera and Selcuk (2009) framework for two reasons. First, in our model, buyers draw idiosyncratic values once they visit a seller; i.e., buyers are ex post heterogeneous. Second, we allow for the possibility that sellers may be ex ante heterogeneous in the sense of having different reservation values.

${ }^{5}$ See also Menzio (2007), who shows that "cheap talk" in the form of non-binding announcements about compensation can, under some circumstances, signal employer type and partially direct worker search. In a similar vein, Kim (2009) analyzes a model in which directed search leads to endogenous segmentation in a market for lemons.
} 
In our model, we assume that buyers can identify these differences, perhaps with the help of real estate agents, perhaps by simply using the web. We are looking at the role that the asking price plays after adjusting for these differences. Sellers set different asking prices, even for houses that are intrinsically identical. These differences reflect the sellers' reservations values. Some are motivated, while others are willing to hold out for a good price.

The remainder of our paper is organized as follows. In the next section, we lay out the structure of the game that we analyze. In Section 3, we analyze the model assuming that all sellers have the same reservation value. In Section 4, we consider the heterogeneous-seller case and analyze the separating equilibrium. The nonexistence of pooling and hybrid equilibria are analyzed in the Appendix (B.1 and B.2). Finally, in Section 5, we conclude.

\section{Basic Model}

We model the housing market as a one-shot game played by $B$ buyers and $S$ sellers of identical houses. We consider a large market so that both $B$ and $S$ go to infinity, but in such a way as to keep $\theta=B / S$, the market tightness, constant. We first analyze the market taking $\theta$ as given. Then, once the equilibrium is characterized for any given $\theta$, we allow for free entry of sellers and examine the efficiency of market equilibrium.

The game has several stages:

1. Each seller posts an asking price $a$.

2. Each buyer observes all posted prices and chooses one seller to visit. There is no coordination among the buyers.

3. Upon visiting a seller, the buyer draws a match-specific value, $x$. The match-specific values are iid draws across buyer-seller pairs from a standard uniform distribution. Buyers do not observe the number of other visitors to the house.

4. The buyer can accept the asking price, $a$, make a counteroffer, or walk away.

5. If no buyer visits, the seller retains the value of her house.

6. If at least one buyer visits, but no buyer accepts the asking price, then the seller can accept or reject the highest counteroffer. If one or more buyers accept the asking price, then an ascending-bid auction ensues among those buyers with reserve price a. In this case, the house is transferred to the highest bidder. 
A buyers who fails to purchase a house receives a payoff of zero. The payoff for a buyer who draws $x$ and then purchases the house is $x-p$, where $p$ is the price that the buyer pays. If no sale is made, the owner of the house retains its value, while a seller who transfers her house to a buyer at price $p$ receives that price as her payoff.

This is a model of directed search in the sense that buyers observe all asking prices and choose which seller to visit based on these asking prices. It differs from many directed search models in that the sellers make a limited commitment to their asking prices. That is, while in the usual directed search model, sellers (or vacancies) fully commit to their posted prices (wages), here the seller makes only a limited commitment. If only one buyer shows up and accepts the asking price, then the seller agrees to sell at that price, but if more buyers show up, the price is bid up. We consider symmetric equilibria in which all buyers use the same strategy. They search optimally given the distribution of posted asking prices and given optimal directed search by other buyers. Buyers bid optimally given the bidding strategy followed by other buyers.

We first consider the case of homogeneous sellers, i.e., the case in which all sellers have the same reservation value $s$. In setting an asking price, each seller anticipates buyer reaction to her posted price given the distribution of asking prices posted by other sellers. When sellers are homogenous, we show that the only role of the asking price is to ensure that houses do not sell below $s$. After considering the homogeneous case, we turn to the heterogeneous case in which sellers differ with respect to their reservation values and seller type is private information. In this case, the asking price also has the potential to signal seller type. We assume that there are two seller types: high types who have reservation value $s$ and low types who have a reservation value that we normalize to zero.

\section{Homogeneous Sellers}

We begin by considering the case in which all sellers have the same reservation value, $s$. We first show that payoff equivalence holds in this setting. In particular, if other buyers distribute themselves randomly across sellers posting asking prices greater than or equal to $s$, an individual buyer finds any asking price in $[s, 1]$ equally attractive. If varying the asking price in $[s, 1]$ does not affect the expected buyer arrival rate, then any asking price $a \geq s$ generates the same expected payoff for sellers.

We next show that any distribution of asking prices on $[s, 1]$ is an equilibrium. If a single seller were to deviate and post an asking price $a^{\prime}<s$, buyers would view this favorably, and the seller's expected arrival rate of visitors would increase. Nonetheless, we show that this seller's expected payoff would be lower than it would have been had 
she posted any $a \geq s$. That is, any distribution of asking prices greater than or equal to the common reservation value constitutes an equilibrium. The derivations of buyer and seller behavior in the homogeneous seller case carry over to the heterogeneous case and so are given in detail here. After showing the existence of equilibrium, we examine efficiency by endogenizing the number of sellers.

\subsection{Buyer Side}

Suppose all sellers post asking prices $a \in[s, 1]$. Suppose provisionally that buyers choose which seller to visit at random, so the number of buyers visiting any particular seller is Poisson with parameter $\theta$. If a buyer visits a seller posting $a$, what bidding function should he use, and what is the expected payoff?

Let $b(x)$ denote the buyer's bid as a function of the value drawn. Let $x^{*}$ be such that $x \geq x^{*}$ leads to a bid of $b(x)=a{ }^{6}$ The bidding function constitutes equilibrium behavior if, given that any other buyers visiting this seller set their bids using $b(x)$, it is optimal for an individual buyer to do the same. Another way to express this is: Let $b\left(x^{\prime} ; x\right)$ denote the bid that a buyer who draws $x$ would make if he were to pretend to have drawn $x^{\prime}$. Let $v\left(x^{\prime} ; x\right)$ be the expected payoff to buyer $x$ who pretends to be type $x^{\prime}$. The function $b(x)=b(x ; x)$ reflects equilibrium behavior if $v(x ; x) \geq v\left(x^{\prime} ; x\right)$ for all $\left(x^{\prime}, x\right)$ pairs.

Suppose the buyer draws $x<s$. The buyer is not willing to offer a price that the seller would accept, so his bid is $b(x)=0$; i.e., the buyer walks away, and his payoff is $v(x)=0$.

Next suppose the buyer draws a value $s \leq x<x^{*}$ and that he bids $b\left(x^{\prime} ; x\right)$, while any other buyers visiting this seller use the bidding function $b(x)$. The number of other buyers visiting this seller is Poisson with parameter $\theta$, so the probability that no other buyer visits this seller and draws a value above $x^{\prime}$ is $e^{-\theta\left(1-x^{\prime}\right)}$. Conditional on getting the house, the buyer's payoff is $x$ minus the price paid. That is,

$$
v\left(x^{\prime} ; x\right)=e^{-\theta\left(1-x^{\prime}\right)}\left(x-b\left(x^{\prime} ; x\right)\right) .
$$

Differentiating with respect to $x^{\prime}$ and evaluating at $x^{\prime}=x$ gives

$$
\theta e^{-\theta(1-x)}(x-b(x ; x))-e^{-\theta(1-x)} \frac{\partial b(x ; x)}{\partial x^{\prime}}=0
$$

that is,

$$
\theta(x-b(x))=\frac{d b(x)}{d x}
$$

\footnotetext{
${ }^{6}$ For high enough asking prices, $x^{*}$ is not relevant, that is, a buyer would not want to bid the asking price even were he to draw $x=1$. That is, $b(1)<a$. As we show below (see equations (4) and (7)), this does not affect the expected payoffs for buyers and sellers.
} 
The initial condition is $b(s)=s$ (a buyer who draws value $s$ only buys the house if it can be purchased at price $s$ ). The solution to this equation is

$$
b(x)=x-\frac{1-e^{-\theta(x-s)}}{\theta} \text { for } s \leq x<x^{*},
$$

and the corresponding value is

$$
v(x)=e^{-\theta(1-x)}\left(\frac{1-e^{-\theta(x-s)}}{\theta}\right) \text { for } s \leq x<x^{*} .
$$

Finally, for $x \geq x^{*}$, the buyer bids $b(x)=a$. The expected payoff is

$$
v(x)=e^{-\theta(1-x)}(x-p(x))
$$

where $p(x)$ is the expected price if he draws $x$ and wins the auction. The buyer wins the auction if and only if no other buyer visits and draws a higher value. This probability is $e^{-\theta(1-x)}$. The price that the winning buyer expects to pay depends on how many other buyers visit and draw values in $\left[x^{*}, x\right)$. Denote the number of other such buyers by $n$. This random variable is Poisson with parameter $\theta\left(x-x^{*}\right)$. Conditional on $n$, the expected price, $p(x ; n)$, paid by a winning buyer who has drawn $x \geq x^{*}$ is

$$
\begin{aligned}
& p(x ; 0)=a \\
& p(x ; n)=\frac{n x+x^{*}}{n+1}=x-\frac{x-x^{*}}{n+1} \text { for } n=1,2, \ldots
\end{aligned}
$$

We then have

$$
\begin{aligned}
x-p(x) & =(x-a) e^{-\theta\left(x-x^{*}\right)}+\sum_{n=1}^{\infty} \frac{\left(x-x^{*}\right) e^{-\theta\left(x-x^{*}\right)}\left(\theta\left(x-x^{*}\right)\right)^{n}}{(n+1) !} \\
& =\left(x^{*}-a\right) e^{-\theta\left(x-x^{*}\right)}+\frac{1-e^{-\theta\left(x-x^{*}\right)}}{\theta}
\end{aligned}
$$

and the expected payoff is

$$
v(x)=e^{-\theta(1-x)}\left(\left(x^{*}-a\right) e^{-\theta\left(x-x^{*}\right)}+\frac{1-e^{-\theta\left(x-x^{*}\right)}}{\theta}\right) \text { for } x^{*} \leq x .
$$

Before taking the final step of solving for $x^{*}$, we can summarize the problem of a buyer who visits a seller posting an asking price of $a \geq s$ as follows:

$$
b(x)= \begin{cases}0 & \text { for } 0 \leq x<s \\ x-\frac{1-e^{-\theta(x-s)}}{\theta} & \text { for } s \leq x<x^{*} \\ a & \text { for } x^{*} \leq x\end{cases}
$$




$$
v(x)= \begin{cases}0 & \text { for } 0 \leq x<s \\ e^{-\theta(1-x)}\left(\frac{1-e^{-\theta(x-s)}}{\theta}\right) & \text { for } s \leq x<x^{*} \\ e^{-\theta(1-x)}\left(\left(x^{*}-a\right) e^{-\theta\left(x-x^{*}\right)}+\frac{1-e^{-\theta\left(x-x^{*}\right)}}{\theta}\right) & \text { for } x^{*} \leq x .\end{cases}
$$

Continuity of $v(x)$ at $x^{*}$ gives

$$
x^{*}-\frac{1-e^{-\theta\left(x^{*}-s\right)}}{\theta}=a .
$$

Using this to substitute for $\left(x^{*}-a\right)$ in (1) gives

$$
x-p(x)=\frac{1-e^{-\theta(x-s)}}{\theta} .
$$

That is, a buyer who draws $x \geq x^{*}$ can expect to pay

$$
p(x)=x-\frac{1-e^{-\theta(x-s)}}{\theta}
$$

if he is the winning bidder.

Substituting for $x^{*}-a$ in $v(x)$ for $x \geq x^{*}$ gives

$$
v(x)=\left\{\begin{array}{ll}
0 & \text { for } 0 \leq x<s \\
\frac{e^{-\theta(1-x)}-e^{-\theta(1-s)}}{\theta} & \text { for } s \leq x
\end{array} .\right.
$$

The expected payoff to a buyer who visits a seller posting $a \geq s$ is thus

$$
V(a ; \theta)=\int_{s}^{1} v(x) d x=\frac{1-e^{-\theta(1-s)}-\theta(1-s) e^{-\theta(1-s)}}{\theta^{2}} .
$$

So long as all sellers posting $a \geq s$ face the same buyer arrival rate, an individual buyer has the same expected payoff if he visits any one of those sellers. In particular, the buyer's expected payoff does not depend on $a$. This implies that buyers can do no better than randomizing their visits over these sellers, as was assumed.

\subsection{Seller Side}

Assuming that buyers arrive at rate $\theta$, we next derive the expected payoff for a seller who posts $a \geq s$. If no buyers visit this seller, she retains $s$. This occurs with probability $e^{-\theta}$. The seller receives at least one visitor with probability $1-e^{-\theta}$. Given that at least one buyer visits, suppose that the highest valuation drawn is $x$. If $x<s$, the seller retains $s$. If $s \leq x<x^{*}$, the seller's payoff is this buyer's bid, $b(x)$. If $x \geq x^{*}$, the seller's expected payoff is $p(x)$. 
The density of the highest $x$ drawn at a particular seller is

$$
f(x \mid \text { high })=\frac{P[\operatorname{high} \mid x] f(x)}{P[\text { high }]}=\frac{\theta e^{-\theta(1-x)}}{1-e^{-\theta}} .
$$

This can be understood as follows. Consider a buyer who draws $x$. The probability that no other buyer visits and draws a higher value is $P[$ high $\mid x]=e^{-\theta(1-x)}$. The assumption that buyer values are uniformly distributed, i.e., $f(x)=1$, implies the ex ante probability (i.e., before knowing how many other buyers will visit and before drawing $x$ ) that this buyer will draw the highest value is

$$
P[h i g h]=\int_{0}^{1} P[\operatorname{high} \mid x] f(x) d x=\frac{1-e^{-\theta}}{\theta} .
$$

We can summarize the above discussion as follows. If buyers arrive at rate $\theta$, the expected payoff for a seller who posts $a \geq s$ is

$\Pi(a ; \theta)=e^{-\theta} s+\left(1-e^{-\theta}\right)\left(\int_{0}^{s} s \frac{\theta e^{-\theta(1-x)}}{\left(1-e^{-\theta}\right)} d x+\int_{s}^{x^{*}} b(x) \frac{\theta e^{-\theta(1-x)}}{\left(1-e^{-\theta}\right)} d x+\int_{x^{*}}^{1} p(x) \frac{\theta e^{-\theta(1-x)}}{\left(1-e^{-\theta}\right)} d x\right)$.

Substituting for $b(x)$ and $p(x)$ from the buyer side gives

$$
\Pi(a ; \theta)=1+(1-s) e^{-\theta(1-s)}-\frac{2\left(1-e^{-\theta(1-s)}\right)}{\theta} .
$$

Again, we have payoff equivalence - so long as buyers visit any seller posting $a \geq s$ with equal probability, the expected payoff associated with posting any $a \geq s$ is the same.

\subsection{Equilibrium}

The next step is to show that if all sellers post asking prices in $[s, 1]$, it is not in the interest of a single seller to deviate to $a^{\prime}<s$. If a seller deviates, she picks the $a^{\prime}<s$ that maximizes her expected payoff. How will buyers react to this deviation? First, any buyer who visits this seller and draws $x \geq a^{\prime}$ will bid $a^{\prime}$. There is no point in making a counteroffer since the seller is posting an asking price below her reservation value. Second, the buyer arrival rate adjusts to reflect the fact that the deviant seller is offering an expected payoff that may differ from $V(a)$. Let $\gamma$ be the arrival rate of buyers to this deviant. This arrival rate is determined by the requirement that buyers must be indifferent between visiting a nondeviant and a deviant seller. Let $V\left(a^{\prime} ; \gamma\right)$ be the expected payoff for a buyer who visits a seller posting $a^{\prime}$ when the expected number of other visitors to this seller is Poisson with parameter $\gamma$. Using the same argument we used to derive equation (5),

$$
V\left(a^{\prime} ; \gamma\right)=\int_{a^{\prime}}^{1} e^{-\gamma(1-x)}\left(\frac{1-e^{-\gamma\left(x-a^{\prime}\right)}}{\gamma}\right) d x=\frac{1-e^{-\gamma\left(1-a^{\prime}\right)}-\gamma\left(1-a^{\prime}\right) e^{-\gamma\left(1-a^{\prime}\right)}}{\gamma^{2}} .
$$


The buyer's indifference condition is $V\left(a^{\prime} ; \gamma\right)=V(a ; \theta)$. Treating $\gamma$ as a function of $a^{\prime}$ and noting that $V(a ; \theta)$ depends neither on $a^{\prime}$ nor on $\gamma$, we have

$$
\frac{\partial V}{\partial a^{\prime}}+\frac{\partial V}{\partial \gamma} \frac{d \gamma}{d a^{\prime}}=0 ; \text { i.e., } \frac{d \gamma}{d a^{\prime}}=-\left(\frac{\partial V}{\partial a^{\prime}}\right) /\left(\frac{\partial V}{\partial \gamma}\right) \text {. }
$$

Substituting for $\partial V / \partial a^{\prime}$ and $\partial V / \partial \gamma$ gives

$$
\frac{d \gamma}{d a^{\prime}}=-\frac{\gamma^{3}\left(1-a^{\prime}\right) e^{-\gamma\left(1-a^{\prime}\right)}}{2\left(1-e^{-\gamma\left(1-a^{\prime}\right)}-\gamma\left(1-a^{\prime}\right) e^{-\gamma\left(1-a^{\prime}\right)}-\frac{\gamma^{2}\left(1-a^{\prime}\right)^{2}}{2} e^{-\gamma\left(1-a^{\prime}\right)}\right)}
$$

The denominator is two times the probability that the deviant seller is visited by 3 or more buyers; thus, $d \gamma / d a^{\prime}<0$, as expected.

Returning to the deviant seller's problem and using the same approach as was used to derive equation (7),

$$
\Pi\left(a^{\prime} ; \gamma\right)=e^{-\gamma} s+\left(1-e^{-\gamma}\right)\left(\int_{0}^{a^{\prime}} s \frac{\gamma e^{-\gamma(1-x)}}{1-e^{-\gamma}} d x+\int_{a^{\prime}}^{1} p(x) \frac{\gamma e^{-\gamma(1-x)}}{1-e^{-\gamma}} d x\right) .
$$

Here $p(x)$ is the price that the buyer who wins the auction can expect to pay. In this case, since counteroffers are not at issue, $x^{*}=a^{\prime}$ and

$$
p(x)=x-\frac{1-e^{-\gamma\left(x-a^{\prime}\right)}}{\gamma} .
$$

Substituting and integrating gives

$$
\Pi\left(a^{\prime} ; \gamma\right)=s e^{-\gamma\left(1-a^{\prime}\right)}+1-e^{-\gamma\left(1-a^{\prime}\right)}-\frac{2\left(1-e^{-\gamma\left(1-a^{\prime}\right)}-\gamma\left(1-a^{\prime}\right) e^{-\gamma\left(1-a^{\prime}\right)}\right)}{\gamma} .
$$

Differentiating with respect to $a^{\prime}$, while taking into account that $\gamma$ varies with $a^{\prime}$ via the buyer indifference condition, gives

$$
\frac{d \Pi\left(a^{\prime} ; \gamma\right)}{d a^{\prime}}=\frac{\partial \Pi\left(a^{\prime} ; \gamma\right)}{\partial a^{\prime}}+\frac{\partial \Pi\left(a^{\prime} ; \gamma\right)}{\partial \gamma} \frac{\partial \gamma}{\partial a^{\prime}}
$$

After substitution and considerable algebra,

$$
\frac{d \Pi\left(a^{\prime} ; \gamma\right)}{d a^{\prime}}=\gamma e^{-\gamma\left(1-a^{\prime}\right)}\left(\begin{array}{c}
1+s-2 a^{\prime} \\
-\left(1-a^{\prime}\right) \frac{1-e^{-\gamma\left(1-a^{\prime}\right)}-\gamma\left(1-a^{\prime}\right) e^{-\gamma\left(1-a^{\prime}\right)}-\frac{\gamma^{2}\left(1+s-2 a^{\prime}\right)\left(1-a^{\prime}\right)}{2} e^{-\gamma\left(1-a^{\prime}\right)}}{1-e^{-\gamma\left(1-a^{\prime}\right)}-\gamma\left(1-a^{\prime}\right) e^{-\gamma\left(1-a^{\prime}\right)}-\frac{\gamma^{2}\left(1-a^{\prime}\right)^{2}}{2} e^{-\gamma\left(1-a^{\prime}\right)}}
\end{array}\right)
$$

This expression is positive for all $a^{\prime}<s$. In short, even though buyers are more likely to visit a seller posting $a^{\prime}<s$, it is not profitable for a seller to post $a^{\prime}<s$. 
The argument just given establishes that if all sellers post asking prices in $[s, 1]$, then no seller wants to deviate to an asking price $a^{\prime}<s$. That is, any distribution of asking prices over $[s, 1]$ is consistent with equilibrium.

In fact, the same argument can be used to rule out the possibility of equilibria in which any measure of sellers posts asking prices below the common reservation value, s. Imagine a candidate equilibrium in which some (or possibly all) sellers post asking prices below $s$. Buyer arrival rates would have adjusted to make each buyer indifferent as to which house he visits. That is, there is a common buyer value $V$ associated with this putative equilibrium. The argument that we made above can be applied to show that any seller posting an asking price below $s$ wants to increase her asking price. Consider a particular seller posting $a<s$. The expected payoff associated with posting a price below $s$ is still given by equation (9) and the arrival rate, $\gamma$, is determined by $V\left(a^{\prime} ; \gamma\right)=V$, where the expression for $V\left(a^{\prime} ; \gamma\right)$ is still given by equation (8). The argument given above shows that this seller's expected payoff increases in her asking price.

We have thus shown:

Proposition 1 Any configuration of asking prices over $[s, 1]$ constitutes an equilibrium of the homogeneous-seller model. All such equilibria are payoff equivalent. Further, there are no equilibria in which any sellers post asking prices below s.

Proposition 1 states that there is an infinity of equilibria in the homogeneous-seller model, but we have shown that all of these equilibria are payoff equivalent. We can thus choose one of these equilibria, for example, the one in which all sellers post $a=s$, to demonstrate some of the properties of equilibrium. In particular, we now show that the probability of sale and the average selling price vary with $\theta$ and $s$, the exogenous parameters of the model, in the expected way.

Consider first the probability that any particular house is sold. This is

$$
P[\text { Sale }]=1-e^{-\theta(1-s)} .
$$

This probability would be the same in any equilibrium in which buyers randomize their visits across sellers. As expected, as the market gets tighter, i.e., as $\theta$ increases, the probability that a house sells increases. In addition, also as expected, as sellers become "less motivated," i.e., as $s$ increases, the probability of a sale decreases.

The average selling price is a bit more complicated. We can write

$$
E[p]=\int_{s}^{1} \frac{p(x) f(x \mid \text { high })}{\int_{s}^{1} f(u \mid \text { high }) d u} d x .
$$

When all sellers post $a=s$, the price paid for a particular house is $p(x)$ (equation 3 ), where $x$ is the valuation drawn by the buyer who purchases the house. Using equation 
(6), the density of $x$ for this buyer is

$$
f(x \mid \text { buy })=\frac{f(x \mid \text { high })}{\int_{s}^{1} f(u \mid \text { high }) d u}=\frac{\theta e^{-\theta(1-x)}}{1-e^{-\theta(1-s)}} .
$$

We thus have

$$
E[p]=\frac{1}{1-e^{-\theta(1-s)}}\left(1+e^{-\theta(1-s)}-2 s e^{-\theta(1-s)}-\frac{2}{\theta}\left(1-e^{-\theta(1-s)}\right)\right) .
$$

It is straightforward, if algebraically tedious, to verify that the average selling price is increasing in $\theta$ and in $s$, as one would expect.

\subsection{Competing Auctions}

Before discussing efficiency, we briefly turn to the issue of competing auctions. Our model is closely related to the competing auctions literature, in particular to Peters and Severinov (1997), who analyze a model of directed search in which sellers compete in auctions rather than prices. That is, each seller announces a reserve price for a secondprice auction; then each buyer, after observing all the posted reserve prices, chooses a seller. Peters and Severinov (1997) consider two cases, one in which buyers learn their valuations after choosing an auction and one in which buyers learn their valuations before choosing an auction. The former case (buyers learn their valuations ex post) is similar to the problem we consider.

The essential difference between our model and that of Peters and Severinov (1997) is that we allow sellers to entertain counteroffers. This opens up the possibility that the good in question may sell at a price below the seller's reserve (or asking) price. However, as Proposition 1 shows, one equilibrium in our model is for all sellers to post $a=s$, and in this case, the issue of counteroffers is moot since buyers know that counteroffers below $s$ will not be accepted.

Our result that all sellers posting an asking price equal to the common reservation value constitutes an equilibrium contradicts Peters and Severinov (1997). Normalizing $s$ to zero, they state (p. 156) "Despite the fact that sellers compete in price in this problem, the reserve price does not fall to zero in equilibrium." This statement is, however, not correct. The equilibrium reserve price in the problem considered in Peters and Severinov (1997) is in fact zero. This can be shown for the case in which valuations are draws from a standard uniform distribution by adapting the argument given above in equations (8) to (10). This is done in Appendix A.

The intuition is that competition precludes the possibility of an inefficient selling mechanism. If the equilibrium reserve price were positive, then some mutually profitable transactions would not be realized; specifically, if the highest valuation drawn at a 
seller were to fall between zero and the positive reserve price. Absent competition, a seller would optimize the tradeoff between extracting as much of the surplus as possible conditional on a sale versus maximizing the probability of a sale. In the limit with full competition, a seller cannot offer buyers a smaller fraction of the surplus than the other sellers do, so it is not possible to post an inefficient mechanism. That is, the equilibrium reserve price must equal the common seller reservation value.

Finally, it is useful to reiterate the difference between our setup and that of Peters and Severinov (1997). In their model, counteroffers are ruled out by assumption, so the asking price is a reserve price. This gives a unique equilibrium in which all sellers post a reserve price equal to their common reservation value. In our model, when counteroffers are allowed, any distribution of asking prices between the common reservation value and the maximum possible valuation for a buyer is an equilibrium, and all of these equilibria are payoff-equivalent. The argument that we used to rule out the possibility that any seller would post $a^{\prime}<s$ is directly applicable to the Peters and Severinov problem. The only difference is that in our problem, the derivative given in equation (10) only applies for asking prices below the reservation value, whereas in the Peters and Severinov problem, because counteroffers are not possible, this derivative applies for reserve prices both above and below the reservation value.

\subsection{Endogenizing $\theta$ - Efficiency}

It is clear that in the model with homogeneous sellers, the mechanism that we analyze is efficient in the sense that once buyers match with sellers, no mutually profitable transactions are left unconsummated. Further, if more than one buyer draws a valuation above the seller's reservation value, the house is necessarily sold to the buyer with the highest valuation. The only remaining efficiency question is whether the buyer/seller ratio is constrained efficient. In order to address this question, we now allow for free entry of sellers. That is, we endogenize $\theta$.

Consider a version of the homogenous-seller model in which the measure of buyers, $B$, is exogenous but the measure of sellers, $S$, is determined by free entry. As before, let $\theta=B / S$. A seller who enters the market pays an advertising cost $A$ and receives expected payoff $\Pi(\theta) .{ }^{7}$ A prospective seller who chooses to stay out of the market retains value $s$. The expected payoff for a buyer is $V(\theta)$. If each seller posts an asking price $a \geq s$ and if buyers randomize their visits across sellers, the buyer and seller values are given by equations (5) and (7), respectively. Equilibrium with endogenous $\theta$ requires that the

\footnotetext{
${ }^{7}$ Here we consider $\Pi$ and $V$ as functions of $\theta$. We suppress $a$ since we showed earlier that $\Pi$ and $V$ do not depend on $a$.
} 
free entry condition

$$
\Pi(\theta)-A=s
$$

is satisfied.

The social planner's objective is to maximize total net surplus for market participants. Total net surplus is

$$
B V(\theta)+S(\Pi(\theta)-A-s) .
$$

Equivalently, since $B$ is exogenous, the social planner objective can be written on a per-buyer basis as

$$
V(\theta)+\frac{\Pi(\theta)-A-s}{\theta},
$$

so the efficient value of $\theta$ solves

$$
V^{\prime}(\theta)+\frac{\theta \Pi^{\prime}(\theta)-(\Pi(\theta)-A-s)}{\theta^{2}}=0 .
$$

Given the free entry condition, equilibrium is efficient if

$$
V^{\prime}(\theta)+\frac{\Pi^{\prime}(\theta)}{\theta}=0 .
$$

From equations (5) and (7), this holds for all $s$. We have thus shown:

Proposition 2 Free entry equilibrium is efficient in the homogeneous-seller case.

\section{Heterogeneous Sellers}

When all sellers have the same reservation value, the asking price plays no role beyond ensuring that houses never sell below that common value. Why then do buyers care about asking prices? The reason, in our view, is that the asking price signals a seller's type, that is, how eager she is to sell her house. We now develop this idea in the heterogeneous-seller version of our model.

We suppose that sellers are heterogeneous with respect to their reservation values. For simplicity, we consider two seller types. A fraction $q$ of sellers, the high $(\mathrm{H})$ types, have reservation value $s$, as in the homogeneous case. The remaining sellers, the low (L) types (the "motivated sellers"), have a lower reservation value, which we normalize to 0. Seller type is private information, but $q$ is common knowledge. Given these assumptions, there are three types of equilibria to consider in which sellers follow pure strategies. In separating equilibrium, each seller posts an asking price that is type-revealing. There are also two types of pooling equilibria to consider - one in which all sellers post asking prices below $s$ ("pooling-on-low") and one in which all sellers post asking prices greater 
than or equal to $s$ ("pooling-on-high"). Finally, hybrid equilibria, in which one seller type randomizes between a high price and a low price, also need to be considered. In a "mixing-by-lows" equilibrium, type-L sellers randomize between posting a low price $(a<s)$ and a high price $(a \geq s)$ while type-H sellers all post a high price, and in a "mixing-by-highs" equilibrium, type-H sellers randomize between posting a low versus a high price, while all type-L sellers post a low price.

The asking price has the potential to signal seller type, but the incentives for one type to mimic the other are not straightforward in our model. Ex ante each seller wants buyers to believe that she is type $\mathrm{L}$ because this increases her expected queue length, but ex post, once buyers have allocated themselves across sellers, every seller wants buyers to believe that she is type $\mathrm{H}$ because this belief leads to higher bids on average. Sellers, however, have only one signal and must trade off the benefit of longer queues in the first stage against higher bids in the second stage. This is why the two types of pooling equilibria and the two types of hybrid equilibria are conceivable in our setting. In short, even though equilibrium refinements can often be used to rule out pooling and hybrid equilibria in signaling models, it is not obvious that this will be the case in our setting.

As it turns out, despite the conflicting incentives to mimic, neither pooling equilibria nor hybrid equilibria exist in our model. That is, there are no equilibria in which any type-H seller "pretends to be a type L" nor are there equilibria in which any type-L seller "pretends to be type H." The ex ante incentive to lower the asking price to attract buyers dominates for type L; the ex post incentive to set a price that elicits higher bids (and ensures that the house will not be sold at a price below $s$ ) dominates for type H.

The equilibrium that does exist separates the two seller types. Type-L sellers post low prices, and type-H sellers post high prices, and there is a separating equilibrium for each parameter combination, $\{q, s, \theta\}$. More precisely, as in the homogeneous-seller case, there is an infinity of equilibria for each parameter configuration, all of which are payoff equivalent. When $q$ is high enough and/or $s$ is low enough and/or $\theta$ is high enough, buyers visit both seller types. Otherwise, the equilibrium is one in which only type-L sellers receive visitors. In any event, that is, for any $\{q, s, \theta\}$ combination, separating equilibrium is efficient. The equilibrium is efficient first in the sense that, once buyers have allocated themselves to sellers, sales are consummated if and only if the net surplus from doing so is positive, and when a house is sold it always goes to the buyer with the highest valuation. This is obvious given the discussion in the preceding paragraph. Second, a social planner would prefer that type-L sellers have longer queues on average than do type-H sellers. Separating equilibrium gets these queue lengths just right. That is, the equilibrium rates at which buyers visit the two seller types equal the rates that the social planner would choose. 
Third, we consider the possibility of entry in the heterogeneous-seller model. Since there are two seller types and the type- $\mathrm{H}$ sellers have the least to gain from entering the market, we endogenize their entry. Separating equilibrium is also efficient in this sense. To understand why, note that efficiency requires that buyers should receive their contribution to the matching process and sellers should receive the rest of the surplus. Consider the case where buyers are identical, i.e., the distribution of $\mathrm{X}$ is degenerate. In this case, a buyer should receive the full surplus if he is alone (without him no transaction would have occurred) and nothing if multiple buyers arrive (since the buyer's presence was not necessary for the transaction). When buyers are not identical, the buyer with the highest valuation above the seller's reservation value should get the house, but what is his marginal contribution? In the absence of the winning buyer, the house would have gone to the buyer with the second highest valuation above the reservation value so the winning buyer should get the difference between the highest and the second highest valuation. This is exactly the expected payoff from the auction. It is important that we allow for auctions as a selling mechanism because price-posting models cannot solve the asymmetric information problem on the buyer side while auctions do. ${ }^{8}$

We analyze separating equilibria and demonstrate their efficiency properties below. Nonexistence of pooling and hybrid equilibria is treated in Appendix B.

\subsection{Separating Equilibrium}

In separating equilibrium, sellers indicate their types by their asking prices - type-L sellers post low prices, and type-H sellers post high prices. Such an equilibrium is defined by three conditions. First, buyers, knowing that a low (high) asking price signals type L (type H), allocate themselves optimally across the two seller types. Second, no type-L seller wants to post a high price. Third, no type-H seller wants to post a low price.

\subsubsection{Buyer Optimality}

We begin with the buyer optimality condition. Suppose each buyer visits a seller posting a high price with probability $r$. In a finite housing market, the number of visitors to a type-H seller would be binomial with parameters $r B$ and $\frac{1}{q S}$. As $B, S \rightarrow \infty$, with $B / S=\theta$, the number of visitors to a type-H seller is thus Poisson with parameter $\theta_{H}=r \theta / q$. Similarly, the number of visitors to a type-L seller is Poisson with parameter $\theta_{L}=(1-r) \theta /(1-q)$.

\footnotetext{
${ }^{8}$ As Eeckhout and Kircher (2010) show, the form of the matching function is also important for efficiency. In the housing market, buyers only bid for one house at a time, so the urn-ball matching technology is the relevant one, but in other markets, different contact technologies may be appropriate and that may affect the efficiency result.
} 
Let $V_{L}(r)$ be the value to a buyer of visiting a seller posting a low price given that all other buyers visit sellers posting a high price with probability $r$. Similarly, let $V_{H}(r)$ be the value to a buyer of visiting a seller posting a high price given that all other buyers visit sellers posting a high price with probability $r$. Using the arguments underlying equation (5), these values are

$$
\begin{aligned}
V_{H}(r) & =\frac{1-e^{-\theta_{H}(1-s)}-\theta_{H}(1-s) e^{-\theta_{H}(1-s)}}{\theta_{H}^{2}} \\
V_{L}(r) & =\frac{1-e^{-\theta_{L}}-\theta_{L} e^{-\theta_{L}}}{\theta_{L}^{2}} .
\end{aligned}
$$

The buyer optimality condition is:

Buyer Optimality:

$$
r>0=>V_{L}(r)=V_{H}(r) \text { and } r=0=>V_{L}(0) \geq V_{H}(0) .
$$

That is, if all buyers visit type-H sellers with probability $r$, then each individual buyer must be indifferent as to which seller type he visits. If all buyers visit only type-L sellers, then no individual buyer can prefer to visit a type-H seller.

For what parameter configurations $\{q, s, \theta\}$ does separation lead to $r>0$ ? For what parameter configurations do buyers only visit sellers posting low prices? Using $\frac{\partial \theta_{H}}{\partial r}=$ $\frac{\theta_{H}}{r}$ and $\frac{\partial \theta_{L}}{\partial r}=-\frac{\theta_{L}}{1-r}$, note first that

$$
\begin{gathered}
V_{H}^{\prime}(r)=-\frac{2}{r}\left(\frac{1-e^{-\theta_{H}(1-s)}-\theta_{H}(1-s) e^{-\theta_{H}(1-s)}-\frac{\theta_{H}^{2}(1-s)^{2} e^{-\theta_{H}(1-s)}}{2}}{\theta_{H}^{2}}\right)<0 \\
V_{L}^{\prime}(r)=\frac{2}{(1-r)}\left(\frac{1-e^{-\theta_{L}}-\theta_{L} e^{-\theta_{L}}-\frac{\theta_{L} e^{-\theta_{L}}}{2}}{\theta_{L}^{2}}\right)>0
\end{gathered}
$$

for $r \in(0,1]$. The signs of these derivatives are intuitive. All else equal, if a single buyer chooses to visit a type-H seller, he is better off doing so when fewer of his fellow buyers visit type-H sellers, i.e., when $r$ is low. The signs of these derivatives imply that $V_{H}(r)-V_{L}(r)$ is decreasing in $r$.

Buyers visit both type-L and type-H sellers with positive probability iff (i) $\lim _{r \rightarrow 0}$ $V_{H}(r)-V_{L}(r)>0$ and (ii) $\lim _{r \rightarrow 1} V_{H}(r)-V_{L}(r)<0$. The second condition is trivially satisfied - if all other buyers visit sellers posting high prices, any individual buyer is clearly better off visiting a seller posting a low price. In fact, when $r=q$, so that 
$\theta_{H}=\theta_{L}$, it is clear that $V_{H}(q)<V_{L}(q)$ so long as $s>0$. To find the parameter values for which condition (i) holds, note that

$$
V_{L}(0)=\frac{1-e^{-\theta /(1-q)}-(\theta /(1-q)) e^{-\theta /(1-q)}}{(\theta /(1-q))^{2}}
$$

and, using l'Hôpital's Rule, that

$$
\lim _{r \rightarrow 0} V_{H}(r)=\frac{(1-s)^{2}}{2} .
$$

Condition (i) is satisfied and thus buyers visit both seller types with positive probability iff

$$
\frac{(1-s)^{2}}{2}>\frac{1-e^{-\theta /(1-q)}-(\theta /(1-q)) e^{-\theta /(1-q)}}{(\theta /(1-q))^{2}} .
$$

When (13) is violated, buyers only visit the type-L sellers.

Finally, we show that for any given values of $\theta$ and $q$, there are values $s>0$ for which this inequality is satisfied, that is, such that $V_{H}(r)=V_{L}(r)$ has a unique positive solution. Let $z=\theta /(1-q)$. Inequality (13) can be written as

$$
(1-s)^{2} \frac{z^{2}}{2}>1-e^{-z}-z e^{-z}
$$

Suppose $s=0$. The inequality then holds for all $z>0$, i.e., so long as $\theta>0$. (At $z=0$, the two sides are equal, and the derivative of the LHS with respect to $z$ exceeds the corresponding derivative of the RHS.) Starting from $s=0$ and a positive value of $z$, if we increase $s$, the RHS of the inequality stays constant while the LHS falls. At $s=1$, the inequality is clearly violated. For given values of $\theta$ and $q$, there is thus a critical value of $s$ below which $V_{H}(r)=V_{L}(r)$ has a unique positive solution. Above that critical value, no buyers visit sellers posting a high price.

\subsubsection{No-Mimic Conditions for Sellers}

The next step is to show that if all type-L sellers post low prices and all type-H sellers post high prices, then no seller wants to deviate from this configuration. We first need expressions for the payoffs that the two seller types can expect to earn in equilibrium, i.e., if they do not deviate. Let $\Pi_{L}\left(a_{L}\right)$ be the expected payoff for a type-L seller who posts a low price (for the moment, $a_{L}$ denotes any low asking price, i.e., any $a<s$ ) conditional on buyers believing that $a_{L}$ signals type L, and let $\Pi_{H}\left(a_{H}\right)$ be the expected payoff for a type-H seller posting a high price conditional on buyers believing that $a_{H}$ signals type $\mathrm{H}$. Using the arguments underlying equation (7), we have

$$
\begin{aligned}
\Pi_{L}\left(a_{L}\right) & =1+e^{-\theta_{L}}-\frac{2\left(1-e^{-\theta_{L}}\right)}{\theta_{L}} \\
\Pi_{H}\left(a_{H}\right) & =1+(1-s) e^{-\theta_{H}(1-s)}-\frac{2\left(1-e^{-\theta_{H}(1-s)}\right)}{\theta_{H}} .
\end{aligned}
$$


We first consider a potential deviation by a type-L seller to a high price, $a_{H}$. Buyers believe that sellers posting $a_{H}$ are type $\mathrm{H}$ with probability 1 and thus visit at rate $\theta_{H}$. The deviant's expected payoff can be calculated as follows. If no buyers visit, the seller retains value 0 . This occurs with probability $e^{-\theta_{H}}$. The seller receives at least one visitor with probability $1-e^{-\theta_{H}}$. Consider a buyer who draws value $x$. What should this buyer do if $x<s$ ? The buyer believes that this seller is type $\mathrm{L}$ with probability 0 . Consistent with our assumption in the homogeneous-seller case, we could assume that the buyer walks away, i.e., bids zero. On the other hand, there is no loss to submitting a bid; i.e., it is weakly dominant for the buyer to bid as if the seller's type were L. We therefore assume that the buyer bids $b(x)$ in this range. ${ }^{9}$ If $s \leq x \leq 1$, the deviant's expected payoff is computed using the argument underlying equation (7) in the homogeneousseller case. In short, the expected payoff for a type-L seller who deviates to a high price is

$$
\begin{aligned}
\Pi_{L}\left(a_{H}\right) & =\int_{0}^{s}\left(x-\frac{1-e^{-\theta_{H} x}}{\theta_{H}}\right) \theta_{H} e^{-\theta_{H}(1-x)} d x+\int_{s}^{1}\left(x-\frac{1-e^{-\theta_{H}(x-s)}}{\theta_{H}}\right) \theta_{H} e^{-\theta_{H}(1-x)} d x \\
& =1+s e^{-\theta_{H}}+(1-s) e^{-\theta_{H}(1-s)}-2\left(\frac{1-e^{-\theta_{H}}}{\theta_{H}}\right) .
\end{aligned}
$$

The no-mimic condition for type-L sellers is $\Pi_{L}\left(a_{L}\right) \geq \Pi_{L}\left(a_{H}\right)$ : No-Mimic Condition for Type-L Sellers:

$$
1+e^{-\theta_{L}}-\frac{2\left(1-e^{-\theta_{L}}\right)}{\theta_{L}} \geq 1+s e^{-\theta_{H}}+(1-s) e^{-\theta_{H}(1-s)}-2\left(\frac{1-e^{-\theta_{H}}}{\theta_{H}}\right)
$$

The no-mimic condition for type-H sellers is a bit more delicate. Consider a potential deviation to a low price just slightly less than $s$. Such a deviation could potentially be profitable for a type-H seller if buyers were to believe that this asking price signals type L with sufficiently high probability. We can, however, circumvent any issues about buyer beliefs in separating equilibrium by considering the case in which all type-L sellers post $a_{L}=0$. Such a posting is consistent with equilibrium play by type-L sellers since the expected payoff for the low type is the same for any asking price, so long as buyers believe the seller is type L with probability one. Further - and this is the crucial point - a buyer who visits a seller posting an asking price of zero doesn't care whether the seller's type is high or low.

Thus, we need only consider a deviation to zero. In this case, buyers arrive at rate $\theta_{L}$. If no buyers visit, the seller retains her value $s$. This occurs with probability $e^{-\theta_{L}}$.

\footnotetext{
${ }^{9}$ This assumption makes the expected payoff for the type-L deviant higher than it otherwise would be. This makes it more difficult to sustain the separating equilibrium. The assumption does not affect the expected payoff for a type- $\mathrm{H}$ seller posting $s$ since a type-H seller would reject any counteroffer below $s$.
} 
The seller receives at least one visitor with probability $1-e^{-\theta_{L}}$. If at least one visitor arrives, the seller's expected payoff follows directly from the homogenous-seller case. In particular,

$$
\begin{aligned}
\Pi_{H}(0) & =e^{-\theta_{L}} s+\int_{0}^{1}\left(x-\frac{1-e^{-\theta_{L} x}}{\theta_{L}}\right) \theta_{L} e^{-\theta_{L}(1-x)} d x \\
& =1+s e^{-\theta_{L}}+e^{-\theta_{L}}-\frac{2\left(1-e^{-\theta_{L}}\right)}{\theta_{L}}
\end{aligned}
$$

The no-mimic condition for type-H sellers is $\Pi_{H}\left(a_{H}\right) \geq \Pi_{H}(0)$ :

No-Mimic Condition for Type-H Sellers:

$$
1+(1-s) e^{-\theta_{H}(1-s)}-\frac{2\left(1-e^{-\theta_{H}(1-s)}\right)}{\theta_{H}} \geq 1+s e^{-\theta_{L}}+e^{-\theta_{L}}-\frac{2\left(1-e^{-\theta_{L}}\right)}{\theta_{L}} .
$$

If $r=0$, i.e., $\theta_{H} \rightarrow 0$, the LHS of Inequality (15) is simply $s$.

Although we have only considered the possibility of a deviation to zero, this does not mean that all type-L sellers necessarily post a common asking price of zero. These sellers can post any distribution of low asking prices, so long as type-H sellers do not want to deviate to the highest price in the support of this distribution.

\subsubsection{Existence of Separating Equilibrium}

Separating equilibrium exists if (i) the buyer optimality condition (12), (ii) the nomimic condition for type-L sellers (14), and (iii) the no-mimic condition for type-H sellers (15) are simultaneously satisfied. If these three conditions hold, buyer beliefs that a low price signals type $\mathrm{L}$ and a high price signals type $\mathrm{H}$ - are necessarily correct in equilibrium.

We establish the existence of separating equilibrium numerically. For any $\{q, s, \theta\}$ combination, we first check to see if inequality (13) is satisfied. If so, we use $V_{L}(r)=$ $V_{H}(r)$ to solve for $r$; if not, we set $r=0$. We then check to see that the two nomimic conditions are satisfied. The shaded areas of Figures 1-3 show the set of $(s, \theta)$ combinations for which $r>0$ for three different values of $q$. Thus, for a wide range of $q$, as long as $s$ is not too high and $\theta$ is not too low, equilibria in which buyers visit both seller types exist. This is intuitive since when $s$ is not too high, buyers do not lose much by visiting a type- $\mathrm{H}$ seller, and when $\theta$ is not too low, the market is relatively tight so buyers have an incentive to visit the type-H sellers. As $q$ increases, there are relatively fewer type-L sellers to visit so buyers have more incentive to visit the type-H sellers. In the non-shaded areas in Figures 1 to 3, where $s$ is relatively high and/or $\theta$ is relatively low, separating equilibria exist with $r=0$, i.e., buyers do not visit the type-H sellers. 


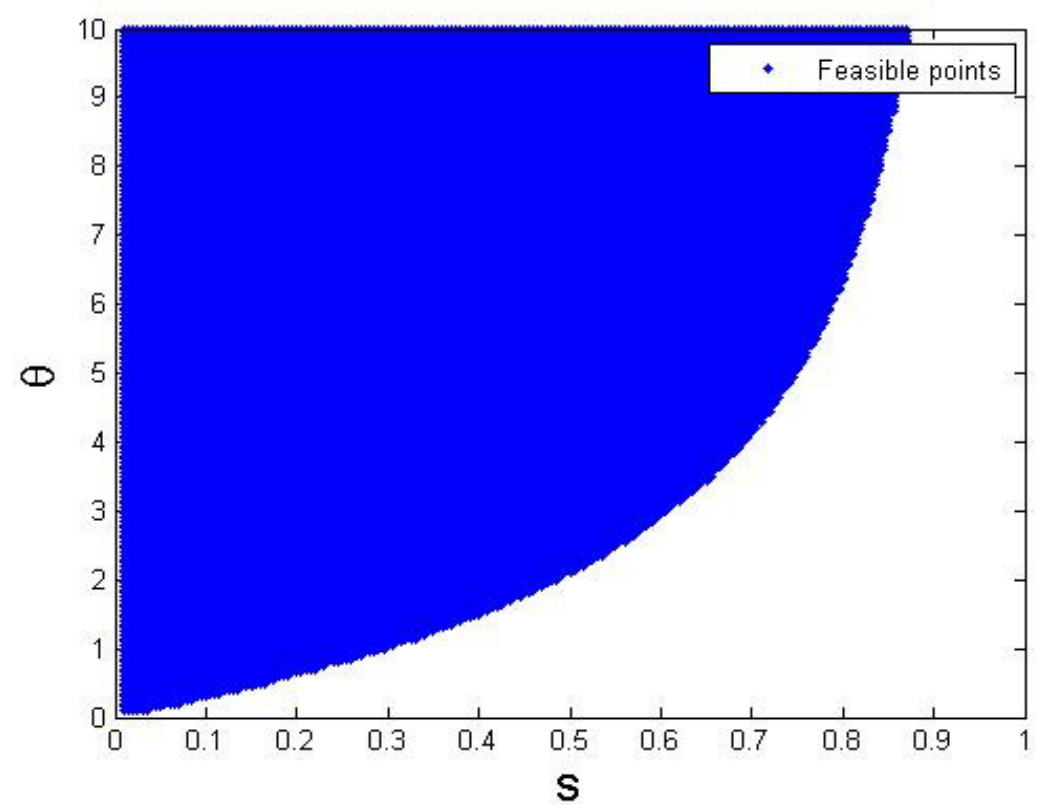

Figure 1: Existence of separating equilibrium with $r>0$ for $q=0.1$

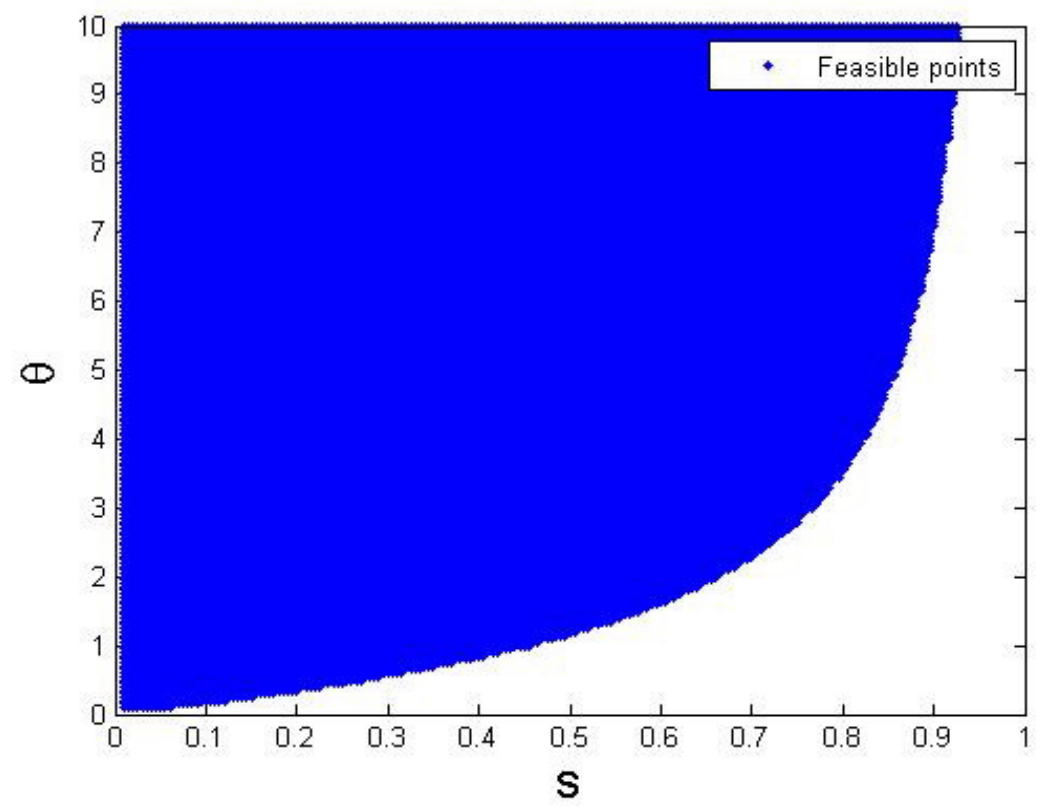

Figure 2: Existence of separating equilibrium with $r>0$ for $q=0.5$ 


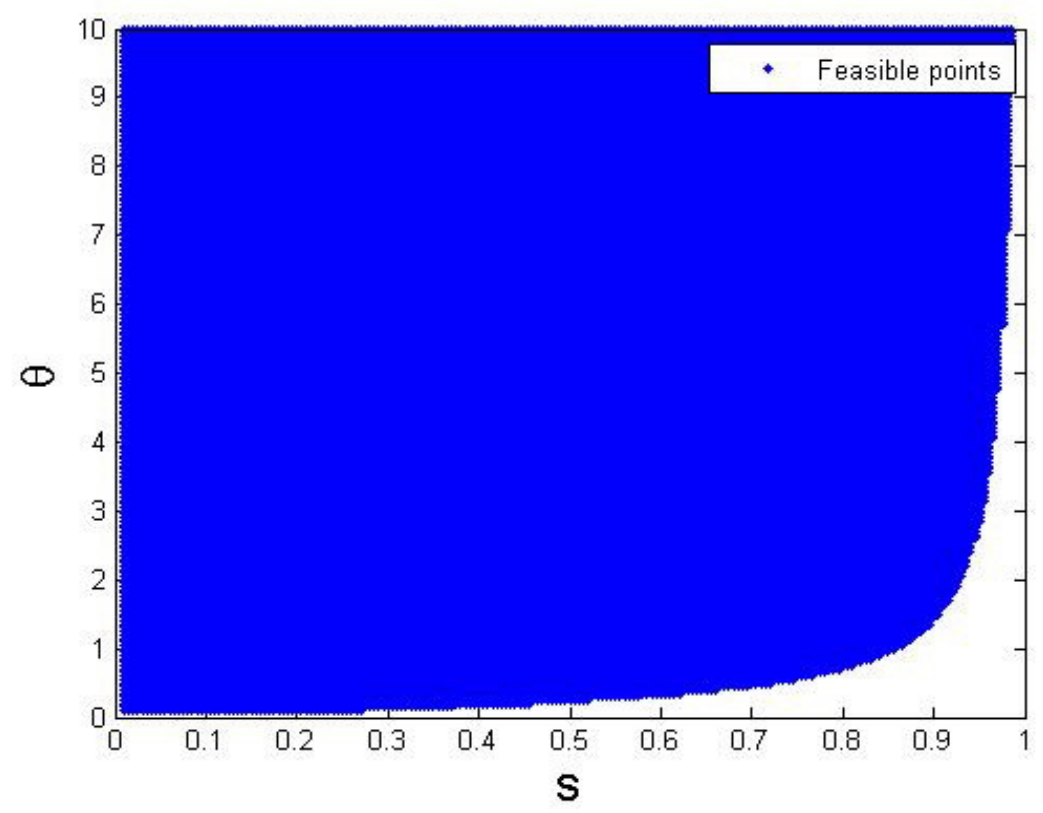

Figure 3: Existence of separating equilibrium with $r>0$ for $q=0.9$

As in the homogeneous-seller model, we again demonstrate some of the properties of our equilibrium by looking at the probability that a house sells and the average selling price. There are now three parameters to consider varying, $q, s$, and $\theta$.

The probability of sale is

$$
P[\text { Sale }]=(1-q) P[\text { Sale } \mid \text { Type } \mathrm{L}]+q P[\text { Sale } \mid \text { Type } \mathrm{H}],
$$

where

$$
\begin{aligned}
P[\text { Sale } \mid \text { Type } \mathrm{L}] & =1-e^{-\theta_{L}} \\
P[\text { Sale } \mid \text { Type } \mathrm{H}] & =1-e^{-\theta_{H}(1-s)} .
\end{aligned}
$$

That is, $P[$ Sale $]$ is a weighted average of the probabilities of sale for type- $\mathrm{L}$ and type$\mathrm{H}$ sellers. The complication in the heterogeneous-seller case is that $\theta_{H}=r \theta / q$ and $\theta_{L}=(1-r) \theta /(1-q)$ vary with $q$ and $\theta$ directly and with $q, \theta$, and $s$ indirectly because $r$ depends on these parameters via the buyer optimality condition. The partial derivatives of $r$ with respect to the parameters are difficult to sign analytically, but even if this were not the case, the effects are not a priori clear. For example, as $s$ goes up, type-H sellers are less attractive so $r$ falls. This means that $\theta_{L}$ goes up and $\theta_{H}$ falls as does $\theta_{H}(1-s)$. Thus, as one would expect the probability of a sale for the type-H sellers is reduced while the probability for the type-L sellers increases, and the effect on the overall probability of a sale is not obvious. The effects of $\theta$ and $q$ are more complicated since variations 


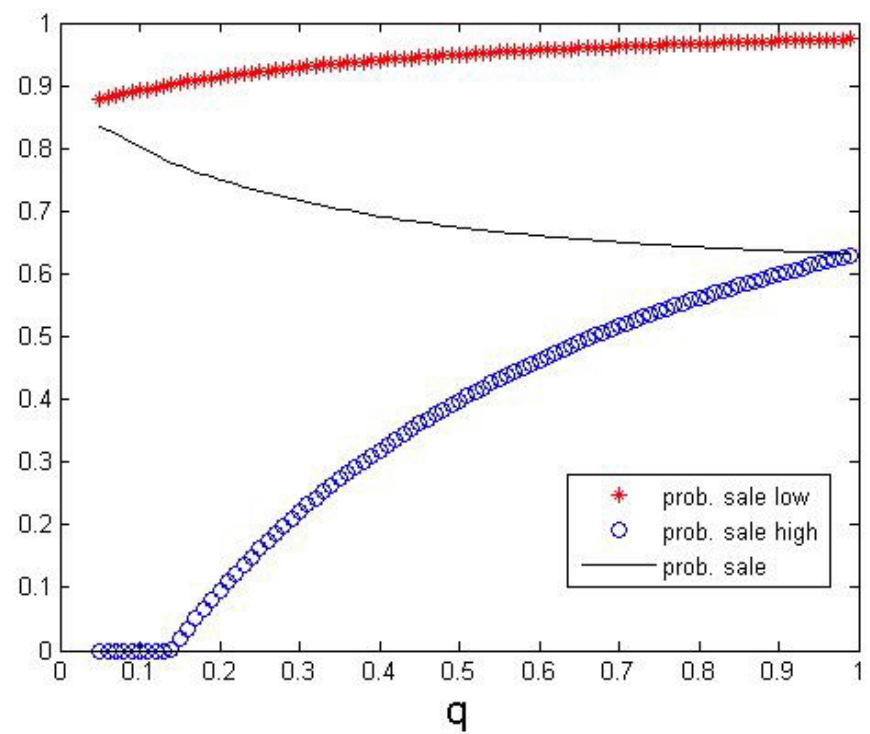

Figure 4: Probability of sale and the fraction of type-H sellers, $\theta=2, s=0.5$

in these parameters affect $\theta_{L}$ and $\theta_{H}$ directly as well as via their effect on $r$. Thus, we illustrate the comparative statics effects numerically.

Figures $4-6$ show how the probability of sale varies with $q, s$, and $\theta$. Each figure is created keeping two parameters constant from the set $\{q, s, \theta\}$ and varying the other. We experimented with many different parameter values for the fixed parameters. For each combination for which a separating equilibrium exists with $r>0$, the signs of the slopes and the positions of the curves relative to each other do not change. First, from Figure 4 (where we set $\theta=2, s=0.5$ ) we see that as the fraction of type-H sellers, $q$, increases, the probability of sale increases both for type-H sellers and for type-L sellers. However, the overall probability of a sale falls because the weight of the type-H sellers (who have a lower sale probability than the type-L sellers) goes up.

Figure 5 (where we set $\theta=2, q=0.5$ ) shows that as the reservation value of the type-H sellers increases, their probability of sale falls (because $r$ goes down) while the probability of sale for the type-L sellers rises. The first effect dominates so the overall probability of a sale goes down. Figure 6 (where we set $s=0.5, q=0.5$ ) shows that as the buyer/seller ratio, $\theta$, rises, the probability of sale rises for both type-L and type-H sellers and the overall probability of a sale goes up as well.

The average selling price is given by

$$
E[p]=\frac{(1-q) P[\text { Sale } \mid \text { Type L }] E[p \mid \text { Type L }]+q P[\text { Sale } \mid \text { Type } \mathrm{H}] E[p \mid \text { Type } \mathrm{H}]}{P[\text { Sale }]},
$$

which is a weighted average of the average selling prices for houses sold by type-L and 


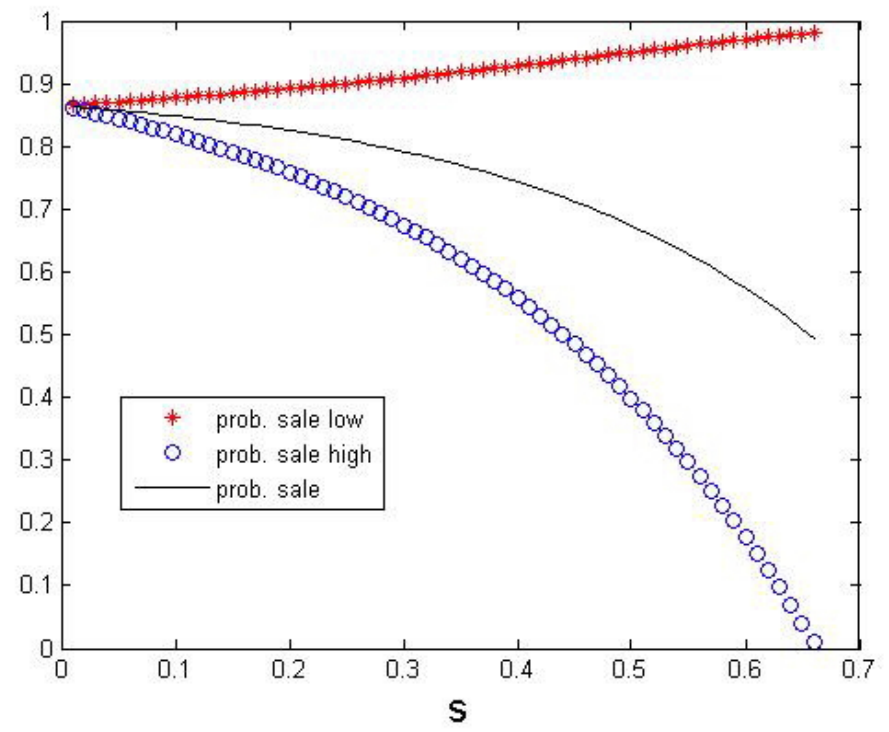

Figure 5: Probability of sale and the reservation value of type- $\mathrm{H}$ sellers, $\theta=2, q=0.5$

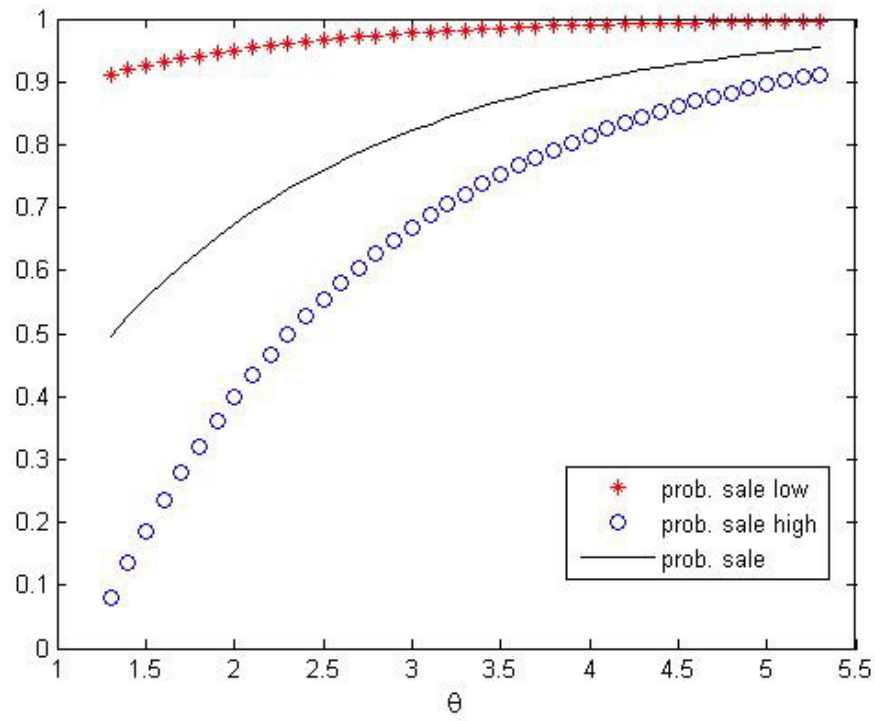

Figure 6: Probability of sale and market tightness, $s=0.5, q=0.5$ 


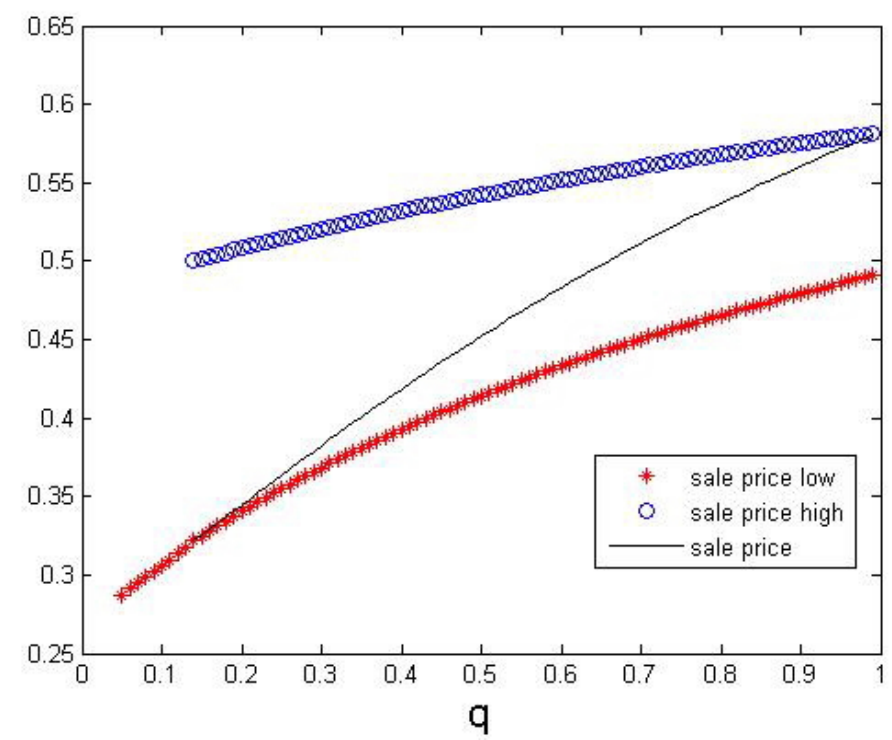

Figure 7: Average selling price and the fraction of type-H sellers, $\theta=2, s=0.5$

type-H sellers. ${ }^{10}$ We have also examined the comparative statics of the average selling price numerically; see Figures 7 - 9. In these Figures we set the exogenous parameters at the same values as in Figures 4 - 6. As expected, the average selling price is increasing in the fraction of type- $\mathrm{H}$ sellers, the reservation value of the type- $\mathrm{H}$ sellers, and in the buyer/seller ratio.

\subsubsection{Efficiency with Exogenous Measures of Sellers}

In separating equilibrium, each buyer visits a type-H seller with probability $r$. Given exogenous measures of buyers and of sellers of each type and given that buyers and sellers transact efficiently once the matching pattern is determined, the only efficiency question is whether the equilibrium value of $r$ equals the value that a social planner would choose.

Suppose the social planner chooses $r$ to maximize total market surplus. To derive an expression for total market surplus, we argue as follows. Consider a type-L seller. If $n$ buyers visit this seller, then the surplus associated with this seller is the highest value drawn by the $n$ visitors. We denote this value by $Y_{n}$. Similarly, the surplus associated with a type-H seller is $\max \left[s, Y_{n}\right]$. The social planner's choice of $r$ determines the distributions of the numbers of visitors for type- $\mathrm{L}$ and type-H sellers. Thus, $r$ determines the expected surplus per type-L and type-H seller, and total market surplus is $\left((1-q) E\left[Y_{n}\right]+q E \max \left[s, Y_{n}\right]\right) S$. Equivalently, since $S$ is fixed, it is convenient to

\footnotetext{
${ }^{10} P[$ Sale $\mid$ Type L $]$ and $P[$ Sale $\mid$ Type $\mathrm{H}]$ are given by (16) and (17) and $E[p \mid$ Type L] is given by (11) with $s=0$ and $\theta$ replaced by $\theta_{L}$ while $E[p \mid$ Type $\mathrm{H}]$ is given by (11) with $\theta$ replaced by $\theta_{H}$.
} 


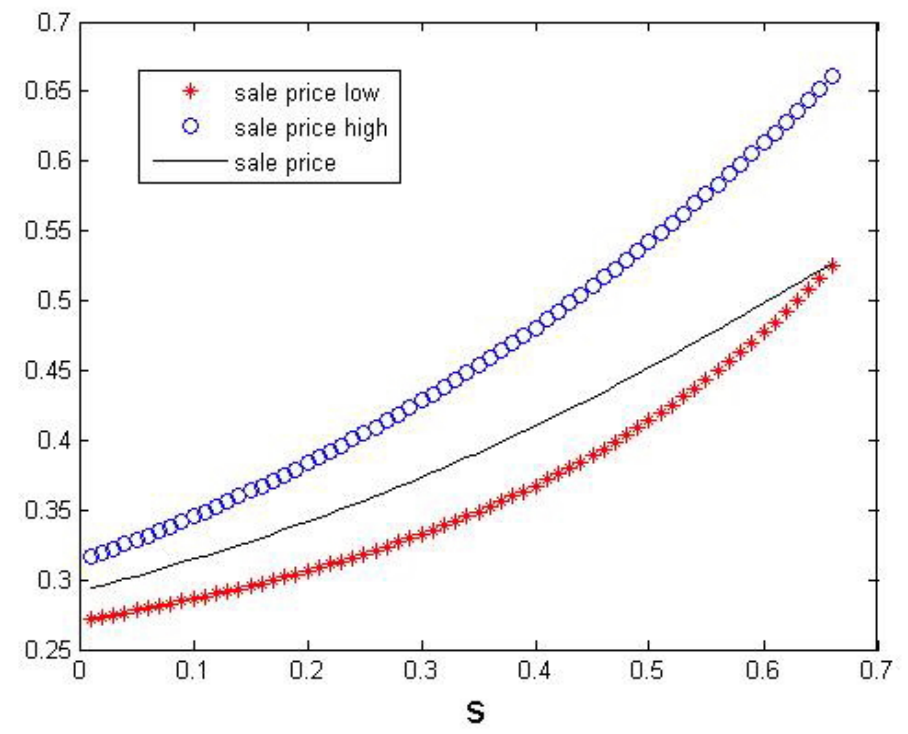

Figure 8: Average selling price and the reservation price of type-H sellers, $\theta=2, q=0.5$

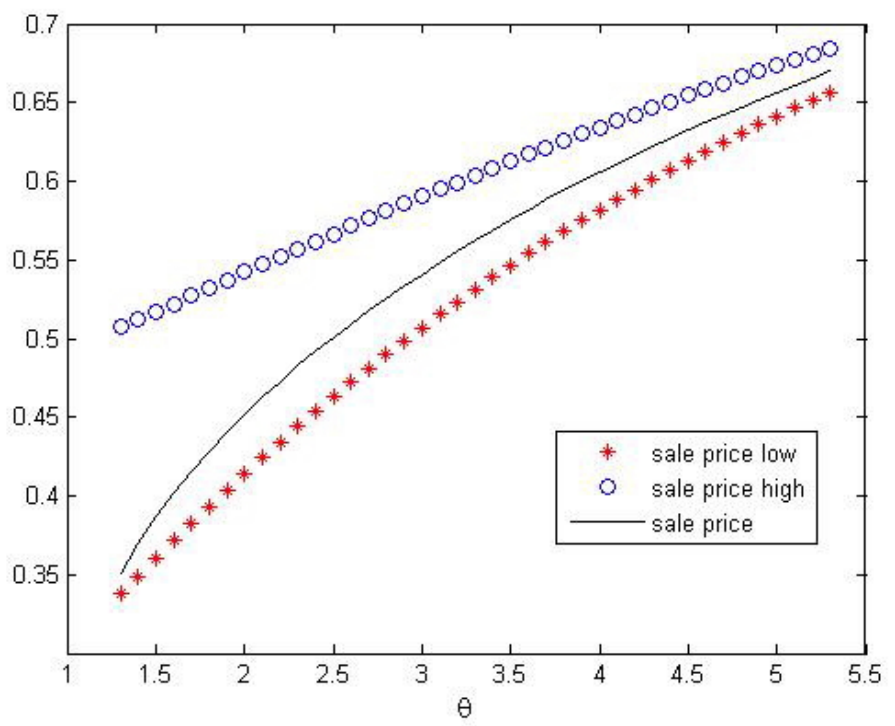

Figure 9: Average selling price and market tightness, $s=0.5, q=0.5$ 
consider the social planner as maximizing the average market surplus per seller.

Now we turn to the problem of computing expected surplus for each type of seller as a function of $r$. Consider a type-L seller. Given $r$, the number of buyers who visit this seller is Poisson with parameter $\theta_{L}$. Conditional on $n$, the expected surplus associated with this seller is $E\left[Y_{n}\right]=\frac{n}{n+1}$; thus, the expected surplus per type-L seller is

$$
\sum_{n=0}^{\infty} \frac{n}{n+1} \frac{e^{-\theta_{L}} \theta_{L}^{n}}{n !}=\frac{1}{\theta_{L}} \sum_{u=1}^{\infty}(u-1) \frac{e^{-\theta_{L}} \theta_{L}^{u}}{u !}=1-\frac{1-e^{-\theta_{L}}}{\theta_{L}}
$$

Similarly, given $r$, the number of buyers visiting a type-H seller is Poisson with parameter $\theta_{H}$. The expected surplus per type-H seller conditional on $n$ is

$$
\begin{aligned}
E \max \left[s, Y_{n}\right] & =s P\left[Y_{n}<s\right]+E\left[Y_{n} \mid Y_{n} \geq s\right] P\left[Y_{n} \geq s\right] \\
& =s^{n+1}+\int_{s}^{1} n y^{n} d y=\frac{n+s^{n+1}}{n+1}
\end{aligned}
$$

Thus, the expected surplus per type-H seller is

$$
\begin{aligned}
\sum_{n=0}^{\infty} \frac{n+s^{n+1}}{n+1} \frac{e^{-\theta_{H}} \theta_{H}^{n}}{n !} & =1-\frac{1-e^{-\theta_{H}}}{\theta_{H}}+\sum_{n=0}^{\infty} \frac{s^{n+1}}{n+1} \frac{e^{-\theta_{H}} \theta_{H}^{n}}{n !} \\
& =1-\frac{1-e^{-\theta_{H}(1-s)}}{\theta_{H}} .
\end{aligned}
$$

The social planner's objective is thus

$$
\max _{r \geq 0}(1-q)\left(1-\frac{1-e^{-\theta_{L}}}{\theta_{L}}\right)+q\left(1-\frac{1-e^{-\theta_{H}(1-s)}}{\theta_{H}}\right)
$$

The first-order condition for the social planner's problem can be expressed as $V_{L}(r) \geq$ $V_{H}(r)$ with equality if $r>0$. This means that whatever the values of $\{q, s, \theta\}$ if all the type-H sellers are posting high prices and all the type-L sellers are posting low prices, the equilibrium value of $r$ and the $r$ that the social planner would choose coincide. That is,

Proposition 3 With $\theta$ exogenous, separating equilibrium is efficient.

\subsubsection{Endogenizing $q$}

We now consider a version of the heterogenous-seller model in which the measures of buyers and of type-L sellers ( $B$ and $L$, respectively) are exogenous but the measure of type-H sellers, $H$, is determined by free entry. We have in mind a situation in which the type-L sellers are "motivated" and have to be in the market, while there is a given stock of type-H homeowners of which some fraction (to be determined endogenously) 
wants to enter the market. ${ }^{11}$ A type-H seller who enters the market pays an advertising $\operatorname{cost} A$ and in equilibrium receives an expected payoff of $\Pi_{H}\left(a_{H}\right)$. A type-H seller who chooses to stay out of the market retains value $s$. Let $B, L \rightarrow \infty$ with $B / L=\xi$. Let the probability that a buyer visits a type-H seller again be $r$. In a finite market, the number of visitors to a type-H seller would be binomial with parameters $r B$ and $\frac{1}{H}$. As $B, H \rightarrow \infty, r B / H=\theta_{H}$, so the number of visitors to a type-H seller is Poisson with parameter $\theta_{H}$. Similarly, the number of visitors to a type-L seller is Poisson with parameter $\theta_{L}=(1-r) B / L=(1-r) \xi$.

A type-H seller only lists her house if the expected payoff exceeds the advertising cost plus the opportunity cost of selling the house, i.e., $A+s$. The extent of entry of type-H sellers is determined by the free entry condition

$$
\Pi_{H}\left(a_{H}\right)=1+(1-s) e^{-\theta_{H}(1-s)}-\frac{2\left(1-e^{-\theta_{H}(1-s)}\right)}{\theta_{H}}=A+s
$$

In order that a separating equilibrium with $H>0$ exist, three additional conditions need to be satisfied. First, $V_{H}(r)=V_{L}(r)$ must have an interior solution; i.e., $r \in(0,1)$. Second, a type-L seller should not want to deviate, i.e., (14) is satisfied. Third, a type-H seller should not want to deviate, i.e., (15) must hold.

There are now two issues to consider. First, for what $(\xi, s)$ combinations does such an equilibrium exist? Second, is entry efficient? To answer the first question, we again compute the equilibrium numerically. The shaded area of Figure 10 shows the range of $(\xi, s)$ combinations for which a free entry separating equilibrium exists. The unshaded area shows the range of parameter values for which type-H sellers do not list their houses.

\subsubsection{Efficiency with Free Entry}

With free entry, we again consider the social planner's problem. It is convenient to formulate the problem on a per-buyer basis. The social planner's objective is to maximize

$$
\frac{L}{B}\left(1-\frac{1-e^{-\theta_{L}}}{\theta_{L}}\right)+\frac{H}{B}\left(1-\frac{1-e^{-\theta_{H}(1-s)}}{\theta_{H}}-(A+s)\right)
$$

by choosing $r$ and $q$. To formulate the problem in a tractable way, we write $H / B, \theta_{L}$, and $\theta_{H}$ in terms of $(r, q)$. Note first that $L / B=\xi$ (exogenous). Then,

$$
\begin{aligned}
\frac{H}{B} & =\frac{H}{L} \frac{L}{B}=\left(\frac{q}{1-q}\right) \frac{1}{\xi}, \\
\theta_{L} & =\frac{(1-r) B}{L}=(1-r) \xi, \\
\theta_{H} & =\frac{r B}{H}=r \xi \frac{(1-q)}{q} .
\end{aligned}
$$

\footnotetext{
${ }^{11}$ In any equilibrium in which type-H sellers choose to enter, all type-L sellers would also find it optimal to enter.
} 


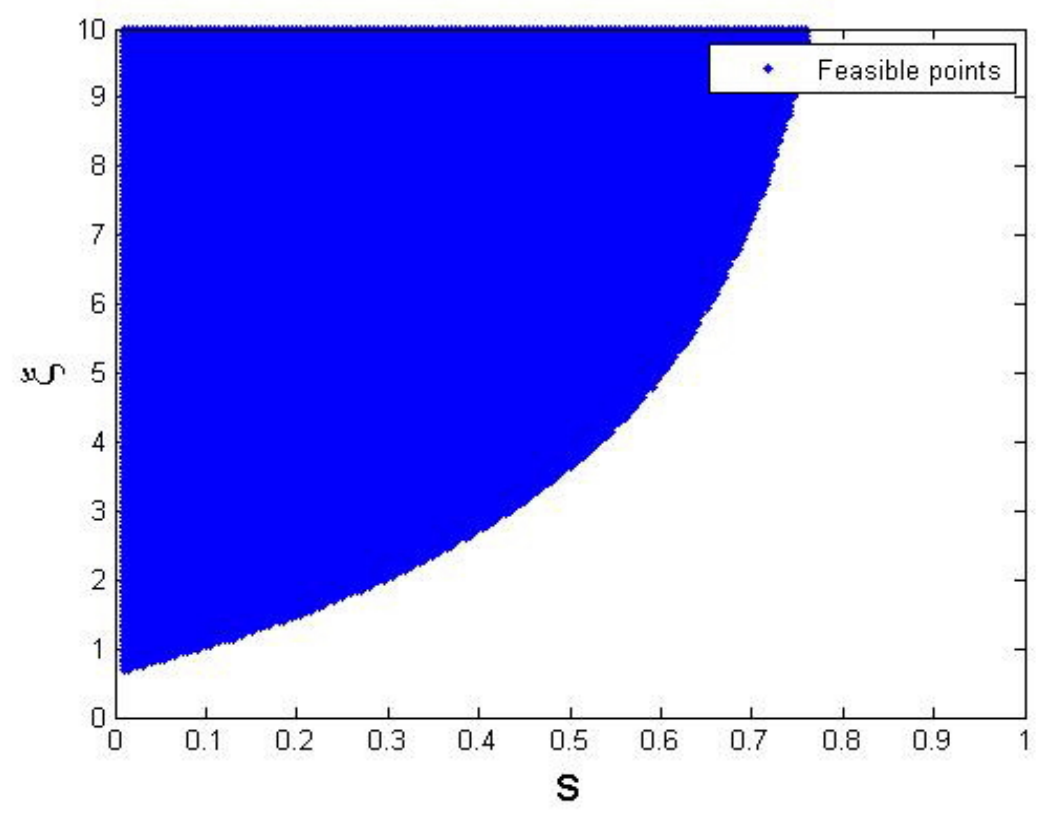

Figure 10: Existence of separating equilibrium with $r>0$ and endogenous $q$

The social planner's problem can now be rewritten as

$$
\max _{r \geq 0, q \geq 0} \xi\left(1-\frac{1-e^{-(1-r) \xi}}{(1-r) \xi}\right)+\left(\frac{q}{1-q}\right)\left(\frac{1}{\xi}\right)\left(1-\frac{1-e^{-r \xi \frac{(1-q)}{q}(1-s)}}{r \xi \frac{(1-q)}{q}}-(A+s)\right) .
$$

We already know that the first-order condition with respect to $r$ gives $V_{L}(r) \geq V_{H}(r)$ with equality if $r>0$; i.e., the equilibrium value of $r$ is efficient whatever the entry decision for type-H sellers. Turning to the first-order condition with respect to $q$, we have

$$
\begin{aligned}
\left(\frac{1}{(1-q) \xi}\right)^{2}\left\{1+(1-s) e^{-r \xi \frac{(1-q)}{q}(1-s)}-\frac{2\left(1-e^{-r \xi \frac{(1-q)}{q}(1-s)}\right)}{r \xi \frac{(1-q)}{q}}-A-s\right\} & =0 \text { if } q>0 \\
& \leq 0 \text { if } q=0 .
\end{aligned}
$$

For an interior solution $(q>0)$, the FOC is the same as (18), the free entry condition, i.e., $\Pi_{H}\left(a_{H}\right)=A+s$.

There are four conceivable situations: (i) $r>0, q>0$, (ii) $r=0, q>0$, (iii) $r>0$, $q=0$, and (iv) $r=0, q=0$. The most interesting is (i) and in this case, the equilibrium is clearly efficient since the FOC for $r$ gives $V_{L}(r)=V_{H}(r)$ and the FOC for $q$ gives the free entry condition. We can rule out case (ii) by noting that $\lim _{r \rightarrow 0} \Pi_{H}\left(a_{H}\right)=s$; i.e., the FOC for $q$ cannot hold with equality. Case (iii) can be ruled out since as $q \rightarrow 0$, $V_{L}(r)>V_{H}(r)$ so that $r=0$. Case (iv) arises when the social planner's problem has a 
corner solution. Again, we have efficiency. The social planner wants to set $q=0$ when $\Pi_{H}\left(a_{H}\right)<A+s$, and when $q=0$, buyers necessarily set $r=0$. We have thus shown:

Proposition 4 The free-entry equilibrium is efficient in the heterogeneous-seller model.

\section{Conclusions}

In this paper, we construct a directed search model of the housing market. The mechanism that we analyze captures important aspects of the way houses are bought and sold in the United States. Sellers post asking prices, and buyers direct their search based on these prices. When a buyer visits a house, he can walk away, make a counteroffer, or offer to pay the asking price. If no buyers offer to pay the asking price, the seller can accept or reject the best counteroffer (if any) that she receives. If at least one buyer offers to pay the asking price, the seller is committed to sell her house at a price equal to the highest bid that follows from the competition among those buyers.

In the homogeneous-seller version of this model, that is, when we assume that all sellers have the same reservation value, $s$, we show that any distribution of asking prices over $[s, 1]$ is consistent with equilibrium. Furthermore, our model implies that houses sometimes sell below, sometimes at, and sometimes above the asking price. Thus, our model is consistent with equilibrium price dispersion for identical houses sold by identical sellers in terms of both asking prices and final sales prices. We also show that free-entry equilibrium is constrained efficient. That is, when sellers have to pay an advertising cost to enter the market, the free-entry and the social planner levels of market tightness coincide.

In the heterogeneous-seller version of the model, only separating equilibria exist. In separating equilibrium, the sellers with the low (high) reservation value identify themselves by posting a low (high) asking price. That is, the asking price also plays a signaling role by allocating buyers across the two seller types. Equilibrium is again constrained efficient. The fraction of buyers who visit high-type sellers and the level of market tightness equal the values that a social planner would choose. Of course, we are not arguing that there are no inefficiencies in the housing market, but rather that the pricing mechanism and the fact that buyers do not directly observe seller types is not a source of inefficiency.

Our paper contributes both to the growing literature that uses equilibrium search theory to model the housing market and to the directed search literature. Our contribution to the housing literature is to build a directed search model that captures the main features of the house-selling process in the United States. We explain the role of the

asking price and its relationship to the sales price, and we show that the mechanism we 
analyze is constrained efficient. Finally, our contribution to the directed search literature is to analyze a model in which there is only limited commitment and the posted price also plays a signaling role.

\section{References}

[1] Albrecht, J., A. Anderson, E. Smith and S. Vroman (2007), Opportunistic Matching in the Housing Market, International Economic Review, 48, 641-64.

[2] Camera, G. and C. Selcuk (2009), Price Dispersion with Directed Search, Journal of the European Economic Association, 7, 1193-1224.

[3] Delacroix A. and S. Shi (2008), Pricing and Signalling with Frictions, mimeo.

[4] De Wit, E. and B. van der Klaauw (2010), Asymmetric Information and List-Price Reductions in the Housing Market, mimeo.

[5] Díaz, A. and B. Jerez (2009), House Prices, Sales and Time on the Market: A Search-Theoretic Approach, mimeo.

[6] Eeckhout J. and P. Kircher (2010), Sorting versus Screening: Search Frictions and Competing Mechanisms, Journal of Economic Theory, 145, 1354-1384.

[7] KyungMin Kim (2009), Endogenous Market Segmentation for Lemons: Theory and Applications, mimeo University of Pennsylvania.

[8] Merlo, A. and F. Ortalo-Magné (2004), Bargaining over Residential Real Estate: Evidence from England, Journal of Urban Economics, 56, 192-216.

[9] Menzio G. (2007), A Theory of Partially Directed Search, Journal of Political Economy, 115, 748-769.

[10] Moen, E. (1997), Competitive Search Equilibrium, Journal of Political Economy, 105, 385-411.

[11] Peters, M. and S. Severinov (1997), Competition among Sellers who Offer Auctions Instead of Prices, Journal of Economic Theory, 75, 141-179.

[12] Wheaton, W. (1990), Vacancy, Search, and Prices in a Housing Market Model, Journal of Political Economy, 98, 1270-92. 


\section{Appendix}

\section{A Competing Auctions}

Peters and Severinov (1997) show in their Lemma 2 (p. 154) that the symmetric equilibrium reserve price, $a$, and the equilibrium buyer/seller ratio, $\theta$, in the competing auctions problem are determined as the solution to (in our notation)

$$
\max _{a^{\prime}, \gamma} \Pi\left(a^{\prime}, \gamma\right) \text { subject to } V\left(a^{\prime}, \gamma\right)=V
$$

where

$$
\begin{aligned}
& \Pi\left(a^{\prime}, \gamma\right)=\gamma \int_{a^{\prime}}^{1} \widetilde{v}(x) e^{-\gamma(1-F(x))} f(x) d x \\
& V\left(a^{\prime}, \gamma\right)=\int_{a^{\prime}}^{1}(1-F(x)) e^{-\gamma(1-F(x))} d x
\end{aligned}
$$

$\widetilde{v}(x)=x-\frac{1-F(x)}{f(x)}$ is the virtual valuation function, and $V$ is the level of market utility. For the case of $X \sim$ unif $[0,1]$ that we consider, it is easy to verify that $V\left(a^{\prime}, \gamma\right)$ and $\Pi\left(a^{\prime}, \gamma\right)$ are given by our equations (8) and (9) with $s=0$. Recognizing that $V\left(a^{\prime}, \gamma\right)=V$ implicitly defines $\gamma=\gamma\left(a^{\prime}\right)$, we can treat the Peters and Severinov problem as one of unconstrained maximization.

The first-order necessary condition for this problem is found by setting $\frac{d \Pi\left(a^{\prime} ; \gamma\left(a^{\prime}\right)\right)}{d a^{\prime}}$, which is given by equation (10), equal to zero (again with $s=0$ ). This derivative equals zero at $a^{\prime}=0$. In addition, the derivative is positive (negative) for $a^{\prime}<0\left(a^{\prime}>0\right)$, so the second-order condition is satisfied. Finally, it is straightforward to show that $a^{\prime}=0$ is a global maximum for this problem. That is, the equilibrium reserve price is zero, contrary to the Peters and Severinov (1997) claim. Finally, since all sellers set $a=0$, buyers randomize their visits, and $\gamma=\theta$.

\section{B Nonexistence of Pooling and Hybrid Equilibria}

\section{B.1 Pooling equilibria}

In this section, we prove the nonexistence of pooling equilibria. In pooling equilibrium, all sellers post the same asking price. There are two cases to consider. First, all sellers could post high prices, i.e., $a \in[s, 1]$; second, they could all post low prices, i.e., $a \in[0, s)$. We refer to the two cases as "pooling on high" and "pooling on low" and analyze them in turn. 


\section{B.1.1 Pooling on High}

We first ask whether an equilibrium can exist in which all sellers post high prices. We proceed as follows. First, we derive the expected payoffs for buyers and for the two seller types assuming $a \geq s$. We show that all high asking prices are payoff equivalent (for buyers, for type-L sellers and for type-H sellers). Second, we consider a deviation by a type-L seller to $a^{\prime}=0$. It is worth noting in this case that buyer beliefs about the deviant type play no role in the analysis. A buyer who visits a deviant posting an asking price of zero doesn't care about the deviant's type. Buyers simply bid the asking price and participate in the auction that follows, so we need not worry about whether buyers' beliefs about out-of-equilibrium play are reasonable or not. Finally, we show that a deviation by the type-L seller to $a^{\prime}=0$ increases her expected payoff. It is thus not in the interest of type-L sellers to mimic type-H sellers, so pooling-on-high equilibria do not exist.

Buyers When all sellers post high prices, a buyer's bidding strategy is characterized by two cutoff values. First, let $\widetilde{x}$ be the value of $x$ such that $x<\widetilde{x}$ leads the buyer to make a bid that only type-L sellers would accept, i.e., $b(x)<s$ for $x<\widetilde{x}$. Second, as in the homogeneous case, let $x^{*}$ be the value of $x$ such that $x \geq x^{*}$ leads to a bid of $b(x)=a$.

Using our results from the homogeneous case, the bid that maximizes the payoff of a buyer who draws $0 \leq x<\widetilde{x}$ is

$$
b(x)=x-\frac{1-e^{-\theta x}}{\theta} \text { for } 0 \leq x<\widetilde{x},
$$

and his expected payoff is

$$
v(x)=(1-q) e^{-\theta(1-x)}\left(\frac{1-e^{-\theta x}}{\theta}\right) \text { for } 0 \leq x<\widetilde{x} .
$$

Next, using the same derivation as in the homogeneous case, the bid that maximizes the payoff of a buyer who draws $x \in\left[\widetilde{x}, x^{*}\right)$ is

$$
b(x)=x-(\widetilde{x}-s) e^{-\theta(x-\widetilde{x})}-\left(\frac{1-e^{-\theta(x-\widetilde{x})}}{\theta}\right) \text { for } \widetilde{x} \leq x<x^{*}
$$

and his expected payoff is

$$
v(x)=e^{-\theta(1-x)}\left((\widetilde{x}-s) e^{-\theta(x-\widetilde{x})}+\left(\frac{1-e^{-\theta(x-\widetilde{x})}}{\theta}\right)\right) \text { for } \widetilde{x} \leq x<x^{*} .
$$

Continuity of $v(x)$ at $\widetilde{x}$ gives

$$
\widetilde{x}=s+(1-q)\left(\frac{1-e^{-\theta \widetilde{x}}}{\theta}\right) .
$$


Substituting this into $b(x)$ and $v(x)$ gives

$$
\begin{aligned}
& b(x)=x-\left(\frac{1-(1-q) e^{-\theta x}-q e^{-\theta(x-\widetilde{x})}}{\theta}\right) \text { for } \widetilde{x} \leq x<x^{*} \\
& v(x)=e^{-\theta(1-x)}\left(\frac{1-(1-q) e^{-\theta x}-q e^{-\theta(x-\widetilde{x})}}{\theta}\right) \text { for } \widetilde{x} \leq x<x^{*} .
\end{aligned}
$$

Finally, a buyer who draws $x \geq x^{*}$ offers to pay the seller's asking price. Using the same derivation as in the homogeneous case, the expected price paid by a buyer who draws $x$ and wins the auction is

$$
p(x)=x-\left(x^{*}-a\right) e^{-\theta\left(x-x^{*}\right)}-\frac{1-e^{-\theta\left(x-x^{*}\right)}}{\theta},
$$

which implies an expected payoff of

$$
v(x)=e^{-\theta(1-x)}\left(\left(x^{*}-a\right) e^{-\theta\left(x-x^{*}\right)}+\frac{1-e^{-\theta\left(x-x^{*}\right)}}{\theta}\right) \text { for } x^{*} \leq x \leq 1 .
$$

Using the continuity of $v(x)$, we have

$$
x^{*}=a+\left(\frac{1-(1-q) e^{-\theta x^{*}}-q e^{-\theta\left(x^{*}-\widetilde{x}\right)}}{\theta}\right),
$$

which, after substitution, gives

$$
p(x)=x-\frac{1-(1-q) e^{-\theta x}-q e^{-\theta(x-\widetilde{x})}}{\theta} .
$$

Substituting this into $v(x)$ gives

$$
v(x)=e^{-\theta(1-x)}\left(\frac{1-(1-q) e^{-\theta x}-q e^{-\theta(x-\widetilde{x})}}{\theta}\right) \text { for } x^{*} \leq x \leq 1 .
$$

We can summarize the problem of a buyer who visits a seller posting an asking price of $a \geq s$ as follows:

$$
\begin{gathered}
b(x)= \begin{cases}x-\frac{1-e^{-\theta x}}{\theta} & \text { for } 0 \leq x<\widetilde{x} \\
x-\left(\frac{1-(1-q) e^{-\theta x}-q e^{-\theta(x-\widetilde{x})}}{\theta}\right) & \text { for } \widetilde{x} \leq x<x^{*} \\
a & \text { for } x^{*} \leq x \leq 1\end{cases} \\
v(x)= \begin{cases}(1-q) e^{-\theta(1-x)\left(\frac{1-e^{-\theta x}}{\theta}\right)} & \text { for } 0 \leq x<\widetilde{x} \\
e^{-\theta(1-x)\left(\frac{1-(1-q) e^{-\theta x}-q e^{-\theta(x-\widetilde{x})}}{\theta}\right)} & \text { for } \widetilde{x} \leq x \leq 1 .\end{cases}
\end{gathered}
$$

Based on the above, the expected payoff to a buyer who visits a seller posting $a \in[s, 1]$ in the putative pooling-on-high equilibrium is

$$
V(a ; \theta)=\frac{1}{\theta^{2}}\left\{1-e^{-\theta}-\theta e^{-\theta}-q\left(e^{-\theta(1-\widetilde{x})}(1+\theta(1-\widetilde{x}))-e^{-\theta}(1+\theta)\right)\right\} .
$$

This expected payoff does not depend on $a$. 
Sellers Next, we compute expected payoffs for the sellers. First, if no buyers visit, a seller retains her value -0 for the type L's and $s$ for the type H's. Given that at least one buyer visits, suppose the highest value drawn by these visitors is $x$. If $0 \leq x<\widetilde{x}$, the type-L seller's payoff is $b(x)$ and the type-H seller's payoff is $s$. For $\widetilde{x} \leq x<x^{*}$, both seller types realize a payoff of $b(x)$ and for $x^{*} \leq x \leq 1$, both seller types realize an expected payoff of $p(x)$. Following the derivation in the homogeneous case for the density of the highest value of $x$ among the buyers visiting a seller,

$$
\begin{gathered}
\Pi_{L}(a ; \theta)=0+\int_{0}^{x^{*}} b(x) \theta e^{-\theta(1-x)} d x+\int_{x^{*}}^{1} p(x) \theta e^{-\theta(1-x)} d x \\
\Pi_{H}(a ; \theta)=e^{-\theta} s+\int_{0}^{\widetilde{x}} s \theta e^{-\theta(1-x)} d x+\int_{\widetilde{x}}^{x^{*}} b(x) \theta e^{-\theta(1-x)} d x+\int_{x^{*}}^{1} p(x) \theta e^{-\theta(1-x)} d x .
\end{gathered}
$$

Substitution gives

$$
\Pi_{L}(a ; \theta)=1-\frac{2\left(1-e^{-\theta}\right)}{\theta}+(1-q(1-\widetilde{x})) e^{-\theta}+q(1-\widetilde{x}) e^{-\theta(1-\widetilde{x})},
$$

which again does not depend on $a$. Similarly, the payoff for the type-H sellers is

$$
\Pi_{H}(a)=e^{-\theta} s+\int_{0}^{\widetilde{x}} s \theta e^{-\theta(1-x)} d x+\int_{\widetilde{x}}^{1}\left(x-\frac{1-(1-q) e^{-\theta x}-q e^{-\theta(x-\widetilde{x})}}{\theta}\right) \theta e^{-\theta(1-x)} d x .
$$

This also does not depend on $a$. That is, all asking prices $a \geq s$ are payoff equivalent for buyers and for the two seller types.

Deviation to $a^{\prime}=0$ We prove nonexistence by showing that it is in the interest of a type-L seller to deviate to $a^{\prime}=0$.

Let $\phi$ be the arrival rate of buyers to the type-L deviant, which is determined via a buyer indifference condition, namely, $V(0 ; \phi)=V(a ; \theta)$, where

$$
V(0 ; \phi)=\frac{1}{\phi^{2}}\left\{1-e^{-\phi}-\phi e^{-\phi}\right\}
$$

That is, $\phi$ is determined by

$$
\frac{1}{\phi^{2}}\left\{1-e^{-\phi}-\phi e^{-\phi}\right\}=\frac{1}{\theta^{2}}\left\{1-e^{-\theta}-\theta e^{-\theta}-q\left(e^{-\theta(1-\widetilde{x})}(1+\theta(1-\widetilde{x}))-e^{-\theta}(1+\theta)\right)\right\},
$$

where $\widetilde{x}$ is given by (19). It is in the interest of the type-L seller to deviate if $\Pi_{L}(0 ; \phi)>$ $\Pi_{L}(a ; \theta)$, that is, if

$$
1+e^{-\phi}-\frac{2\left(1-e^{-\phi}\right)}{\phi}>1-\frac{2\left(1-e^{-\theta}\right)}{\theta}-q(1-\widetilde{x}) e^{-\theta}+q(1-\widetilde{x}) e^{-\theta(1-\widetilde{x})} .
$$


Proof that deviation is profitable When $s=0, \widetilde{x}=0, \phi=\theta$, and the two sides of (22) are equal. Now increase $s$ holding $q$ and $\theta$ constant, taking into account that $\widetilde{x}$ and $\phi$ depend on $s$. Differentiating (19) with respect to $s$ gives

$$
\frac{\partial \widetilde{x}}{\partial s}=\frac{1}{1-(1-q) e^{-\theta \widetilde{x}}}
$$

Similarly, differentiating (21) with respect to $s$, taking into account that $\widetilde{x}$ varies with $s$ gives

$$
\frac{\partial \phi}{\partial s}=\frac{\phi^{3} q(1-\widetilde{x}) e^{-\theta(1-\widetilde{x})}}{2\left(1-e^{-\phi}-\phi e^{-\phi}-\frac{\phi^{2}}{2} e^{-\phi}\right)\left(1-(1-q) e^{-\theta \widetilde{x}}\right)} .
$$

Now we return to inequality (22). Again, when $s=0$, the two sides are equal. We want to increase $s$ and show that the LHS rises more than the RHS. The derivative of the LHS of (22) with respect to $s$ is

$$
\begin{aligned}
\frac{\partial L H S}{\partial s} & =\left(\frac{2\left(1-e^{-\phi}-\phi e^{-\phi}-\frac{\phi^{2}}{2} e^{-\phi}\right)}{\phi^{2}}\right) \frac{\partial \phi}{\partial s} \\
& =\left(\frac{2\left(1-e^{-\phi}-\phi e^{-\phi}-\frac{\phi^{2}}{2} e^{-\phi}\right)}{\phi^{2}}\right)\left(\frac{\phi^{3} q(1-\widetilde{x}) e^{-\theta(1-\widetilde{x})}}{2\left(1-e^{-\phi}-\phi e^{-\phi}-\frac{\phi^{2}}{2} e^{-\phi}\right)\left(1-(1-q) e^{-\theta \widetilde{x}}\right)}\right) \\
& =\frac{\phi q(1-\widetilde{x}) e^{-\theta(1-\widetilde{x})}}{1-(1-q) e^{-\theta \widetilde{x}}},
\end{aligned}
$$

and the derivative of the RHS is

$$
\begin{aligned}
\frac{\partial R H S}{\partial s} & =\left(q e^{-\theta}-q e^{-\theta(1-\widetilde{x})}+\theta q(1-\widetilde{x}) e^{-\theta(1-\widetilde{x})}\right) \frac{\partial \widetilde{x}}{\partial s} \\
& =\frac{q e^{-\theta}-q e^{-\theta(1-\widetilde{x})}+\theta q(1-\widetilde{x}) e^{-\theta(1-\widetilde{x})}}{1-(1-q) e^{-\theta \widetilde{x}}} .
\end{aligned}
$$

To prove that (22) holds, we thus need to show that

$$
\frac{\phi q(1-\widetilde{x}) e^{-\theta(1-\widetilde{x})}}{1-(1-q) e^{-\theta \widetilde{x}}}>\frac{q e^{-\theta}-q e^{-\theta(1-\widetilde{x})}+\theta q(1-\widetilde{x}) e^{-\theta(1-\widetilde{x})}}{1-(1-q) e^{-\theta \widetilde{x}}}
$$

This is equivalent to showing that

$$
\phi(1-\widetilde{x}) e^{-\theta(1-\widetilde{x})}>e^{-\theta}-e^{-\theta(1-\widetilde{x})}+\theta(1-\widetilde{x}) e^{-\theta(1-\widetilde{x})}
$$

or, equivalently,

$$
(1-\widetilde{x}) e^{-\theta(1-\widetilde{x})}(\phi-\theta)+\left(e^{-\theta(1-\widetilde{x})}-e^{-\theta}\right)>0,
$$

which is indeed true. $Q E D$. 


\section{B.1.2 Pooling on Low}

Suppose all sellers post low asking prices, $a \in[0, s)$. We first argue that if $a>0$, then type-L sellers want to deviate to $a^{\prime}=0$. The argument is the same as the one given above for the nonexistence of pooling-on-high equilibria, except that the role of $s$ is played by $a$. We can therefore restrict our attention to a potential pooling-on-low equilibrium in which all sellers post $a=0$.

Now suppose all sellers post $a=0$. Let $\Pi_{H}(0 ; \theta)$ be the expected payoff for a type-H seller who posts $a=0$ in the putative pooling-on-low equilibrium, and let $\Pi_{H}\left(a^{\prime} ; \xi\right)$ be the expected payoff that the type-H seller would expect to receive were she to deviate to $a^{\prime} \geq s$ and receive visits from buyers at rate $\xi$. Note that $\Pi_{H}\left(a^{\prime} ; 0\right)=s-$ even if the deviant seller receives no visitors $(\xi=0)$, she retains her reservation value $s$.

Restricting our attention to values of $(s, \theta)$ such that $\Pi_{H}(0 ; \theta) \geq s$ (otherwise the type-H seller clearly wants to deviate), our results from the homogeneous case give

$$
\begin{aligned}
\Pi_{H}(0 ; \theta) & =s e^{-\theta}+1+e^{-\theta}-\frac{2\left(1-e^{-\theta}\right)}{\theta} \\
\Pi_{H}\left(a^{\prime} ; \xi\right) & =1+(1-s) e^{-\xi(1-s)}-\frac{2\left(1-e^{-\xi(1-s)}\right)}{\xi} .
\end{aligned}
$$

To prove the nonexistence of pooling-on-low equilibria, we thus need to show

$$
1+(1-s) e^{-\xi(1-s)}-\frac{2\left(1-e^{-\xi(1-s)}\right)}{\xi}>s e^{-\theta}+1+e^{-\theta}-\frac{2\left(1-e^{-\theta}\right)}{\theta},
$$

where $\xi$ is determined by the buyer indifference condition.

$$
\frac{1-e^{-\xi(1-s)}-\xi(1-s) e^{-\xi(1-s)}}{\xi^{2}}=\frac{1-e^{-\theta}-\theta e^{-\theta}}{\theta^{2}} .
$$

Note that buyer beliefs about the deviant type come into play at this point. The LHS of (24) is computed assuming that buyers believe the deviant to be type $\mathrm{H}$.

In fact, we show that it is in the interest of a type $\mathrm{H}$ seller to deviate to $a^{\prime} \geq s$ for any belief about her type. First, suppose buyers believe that the deviant type-H seller is of type L. Then, clearly, the deviation is profitable because (i) the arrival rate is the same as for the nondeviants, (ii) if the highest bid is above $s$, the deviant is as well off as she would have been as a nondeviant, and (iii) if the highest bid is below $s$, the deviant is better off. Next, suppose buyers believe the deviant is of type H. We show below that the deviation is also profitable. Finally, if buyers believe the deviant is of type $\mathrm{H}$ with some probability, the deviation is some weighted average of two payoffs which are greater than the payoffs of the nondeviants.

To show that the deviation by a type-H seller is profitable when buyers identify the deviant seller's type correctly, we follow the same strategy as we used for our proof of 
nonexistence of pooling-on-high equilibria. When $s=0, \xi=\theta$ and the two sides of (23) are equal. We thus need to show that the derivative of the LHS of (23) is greater than the derivative of the RHS. The derivative of the RHS is simply $e^{-\theta}$, so we need to show that the LHS derivative exceeds this value.

Note first from (24) that

$$
\frac{\partial \xi}{\partial s}=\frac{-\xi^{3}(1-s) e^{-\xi(1-s)}}{2\left(1-e^{-\xi(1-s)}-\xi(1-s) e^{-\xi(1-s)}-\frac{\xi^{2}(1-s)^{2}}{2} e^{-\xi(1-s)}\right)}
$$

It then follows that

$$
\frac{\partial \xi(1-s)}{\partial s}=-\xi\left(\frac{1-e^{-\xi(1-s)}-\xi(1-s) e^{-\xi(1-s)}}{1-e^{-\xi(1-s)}-\xi(1-s) e^{-\xi(1-s)}-\frac{\xi^{2}(1-s)^{2}}{2} e^{-\xi(1-s)}}\right) .
$$

Now we can differentiate the LHS of (23) with respect to $s$ :

$$
\begin{aligned}
\frac{d \Pi_{H}\left(a^{\prime} ; \xi\right)}{d s}= & -\left(\frac{\xi(1-s) e^{-\xi(1-s)}-2\left(1-e^{-\xi(1-s)}\right)}{\xi(1-s)}\right) \\
& +(1-s)\left(\frac{\partial \xi(1-s)}{\partial s}\right)\left(\frac{\partial\left(\frac{\xi(1-s) e^{-\xi(1-s)}-2\left(1-e^{-\xi(1-s)}\right)}{\xi(1-s)}\right)}{\partial \xi(1-s)}\right)
\end{aligned}
$$

Using

$$
\frac{\partial\left(\frac{\xi(1-s) e^{-\xi(1-s)}-2\left(1-e^{-\xi(1-s)}\right)}{\xi(1-s)}\right)}{\partial \xi(1-s)}=\frac{2\left(1-e^{-\xi(1-s)}-\xi(1-s) e^{-\xi(1-s)}-\frac{\xi^{2}(1-s)^{2}}{2} e^{-\xi(1-s)}\right)}{\xi^{2}(1-s)^{2}}
$$

and substituting for $\frac{\partial \xi(1-s)}{\partial s}$ gives an expression for the derivative of the LHS of (23) with respect to $s$, which, after considerable algebra, reduces to

$$
\frac{\partial \prod_{H}\left(a^{\prime} ; \xi\right)}{\partial s}=e^{-\xi(1-s)}
$$

Since $\xi(1-s)<\theta$, it is immediate that $e^{-\xi(1-s)}>e^{-\theta}$; i.e., the derivative of the LHS of (23) is greater than the derivative of the RHS. QED.

It is straightforward to check these analytical proofs using numerical methods. For arbitrary $\{q, s, \theta\}$, it is easy to check that (22) holds when $\phi$ is determined by (21). Similarly, when $\xi>0$ is determined by (24), one can verify that (23) is satisfied.

\section{B.2 Hybrid Equilibria}

We now consider hybrid equilibria. There are two types of these equilibria to consider (i) an equilibrium in which all type-H sellers post $a \geq s$ but type-L sellers mix between 
posting $a<s$ and posting $a \geq s$ and (ii) an equilibrium in which all type-L sellers post $a<s$ but type-H sellers mix between posting $a<s$ and posting $a \geq s$. It is intuitive that hybrid equilibria cannot exist in this setting. Consider, for example, mixing by lows. Existence of separating equilibrium implies that a type-L seller prefers posting a low price to a high price when all other type-L sellers post low prices. Nonexistence of pooling-on-high equilibrium implies that the type-L seller prefers posting a low price when all other type-L sellers post high prices. Mixing-by-lows is the intermediate case. We now describe how we verify this intuition for the nonexistence of hybrid equilibria numerically.

\section{B.2.1 Mixing by Lows}

Suppose all type-H sellers post high prices while type-L sellers mix between posting a high price with probability $m$ and $a=0$ with probability $1-m$. The question is whether this can be an equilibrium for some $m \in(0,1)$.

Suppose buyers visit sellers posting high prices with probability $r \in(0,1)$. This occurs if

$$
V(0 ; m, r)=V(a ; m, r)
$$

The arrival rate of buyers to sellers posting $a \geq s$ is

$$
\theta_{H}=\frac{r \theta}{q+m(1-q)}
$$

Similarly, the arrival rate to sellers posting $a=0$ is

$$
\theta_{L}=\frac{(1-r) \theta}{(1-m)(1-q)}
$$

Using our results from separating equilibrium,

$$
V(0 ; m, r)=\frac{1-e^{-\theta_{L}}-\theta_{L} e^{-\theta_{L}}}{\theta_{L}^{2}} .
$$

To derive an expression for $V(a ; m, r)$, let

$$
\widehat{q}=\frac{q}{q+m(1-q)}
$$

be the fraction of sellers posting $a \geq s$ who are type H. We can then use our results from pooling on high replacing $q$ with $\widehat{q}$ and $\theta$ with $\theta_{H}$ in equation (20) to get

$$
V(a ; m, r)=\frac{1}{\theta_{H}^{2}}\left\{1-e^{-\theta_{H}}-\theta e^{-\theta_{H}}-\widehat{q}\left(e^{-\theta_{H}(1-\widetilde{x})}\left(1+\theta_{H}(1-\widetilde{x})\right)-e^{-\theta_{H}}(1+\theta)\right)\right\},
$$


where $\widetilde{x}$ is implicitly defined by

$$
(1-\widehat{q})\left(1-e^{-\theta_{H} \widetilde{x}}\right)=\theta_{H}(\widetilde{x}-s)
$$

The value of $m$ is determined by a no-deviation condition,

$$
\Pi_{L}(0 ; m, r)=\Pi_{L}(a ; m, r)
$$

that is, type-L sellers should be indifferent between posting $a=0$ and a high price. Using our separating equilibrium results,

$$
\Pi_{L}(0 ; m, r)=1+e^{-\theta_{L}}-\frac{2\left(1-e^{-\theta_{L}}\right)}{\theta_{L}} .
$$

From our pooling-on-high results,

$$
\Pi_{L}\left(a_{H} ; m, r\right)=1-\frac{2}{\theta_{H}}\left(1-e^{-\theta_{H}}\right)+\widehat{q}(1-\widetilde{x}) e^{-\theta_{H}(1-\widetilde{x})}+(1-\widehat{q}(1-\widetilde{x})) e^{-\theta_{H}} .
$$

To check for the existence of a mixing-by-lows equilibrium, we need to see whether the two equations

$$
\begin{aligned}
V(0 ; m, r) & =V(a ; m, r) \\
\Pi_{L}(0 ; m, r) & =\Pi_{L}(a ; m, r)
\end{aligned}
$$

have a solution for $(m, r) \in(0,1) \times(0,1)$.

We show numerically that this is not the case for a wide range of plausible parameter values. Thus, we conclude that this type of mixing equilibrium does not exist.

\section{B.2.2 Mixing by Highs}

Finally, we consider an equilibrium in which all type-L sellers post $a_{L}<s$ while type-H sellers post $a_{H} \geq s$ with probability $n$ and $a_{L}<s$ with probability $1-n$. The arrival rate of buyers to sellers posting $a_{H}$ is

$$
\theta_{H}=\frac{r \theta}{n q} .
$$

Similarly, the arrival rate to sellers posting $a_{L}$ is

$$
\theta_{L}=\frac{(1-r) \theta}{1-q+(1-n) q}=\frac{(1-r) \theta}{1-n q}
$$

Let $\widetilde{q}$ be the fraction of sellers posting $a_{L}$ who are type $\mathrm{H}$. We have

$$
\widetilde{q}=\frac{(1-n) q}{1-n q} .
$$


The buyer indifference condition is

$$
V\left(a_{L} ; n, r\right)=V\left(a_{H} ; n, r\right)
$$

The value to a buyer who visits a seller posting $a_{L}$ can be taken from our pooling-on-low results replacing $\theta$ with $\theta_{L}$ and $q$ with $\widetilde{q}$. We have

$$
V\left(a_{L} ; n, r\right)=\frac{1-\widetilde{q} e^{-\theta_{L}(1-\widetilde{x})}\left(1+\theta_{L}(1-\widetilde{x})\right)-(1-\widetilde{q}) e^{-\theta_{L}}\left(1+\theta_{L}\right)}{\theta_{L}^{2}},
$$

where

$$
\widetilde{x}=a_{L}+(1-\widetilde{q})\left(\frac{1-e^{-\theta_{L} \widetilde{x}}}{\theta_{L}}\right) .
$$

The value to a buyer of visiting a seller posting $a_{H}$ can be taken from our results on separating equilibrium:

$$
V\left(a_{H} ; n, r\right)=\frac{1-e^{-\theta_{H}(1-s)}-\theta_{H}(1-s) e^{-\theta_{H}(1-s)}}{\theta_{H}^{2}} .
$$

The seller indifference condition is

$$
\Pi_{H}\left(a_{L} ; n, r\right)=\Pi_{H}\left(a_{H} ; n, r\right) .
$$

We take $\Pi_{H}\left(a_{L} ; n, r\right)$ from our pooling-on-low results; we take $\Pi_{H}\left(a_{H} ; n, r\right)$ from our results on separating equilibrium. Specifically,

$$
\begin{aligned}
& \Pi_{H}\left(a_{L} ; n, r\right)=1+s e^{-\theta_{L}(1-\widetilde{x})}-\frac{2\left(1-e^{-\theta_{L}(1-\widetilde{x})}\right)}{\theta_{L}}+e^{-\theta_{L}(1-\widetilde{x})}[q(1-\widetilde{x})-\widetilde{x}]+e^{-\theta_{L}}(1-q)(1-\widetilde{x}) \\
& \Pi_{H}\left(a_{H} ; n, r\right)=1+(1-s) e^{-\theta_{H}(1-s)}-\frac{2\left(1-e^{-\theta_{H}(1-s)}\right)}{\theta_{H}}
\end{aligned}
$$

Again, for an equilibrium to exist, it must be the case that the payoffs for buyers applying to sellers posting the two different asking prices must be equal and the expected payoffs for the type-H sellers must be equal regardless of the asking price they post. That is, the two equations

$$
\begin{gathered}
V\left(a_{L} ; n, r\right)=V\left(a_{H} ; n, r\right) \\
\Pi_{H}\left(a_{L} ; n, r\right)=\Pi_{H}\left(a_{H} ; n, r\right)
\end{gathered}
$$

must have a solution for $(n, r) \in(0,1) \times(0,1)$. We show numerically that this is not the case for a wide range of plausible parameter values. Thus, we conclude that this type of equilibrium does not exist. 